\title{
Thermodynamics and Mechanical Equivalent of Heat
}

\author{
Nahum Kipnis
}

Published online: 1 May 2014

(C) Springer Science+Business Media Dordrecht 2014

\begin{abstract}
This paper is the first part of a three-part project 'How the principle of energy conservation evolved between 1842 and 1870: the view of a participant'. This paper aims at showing how the new ideas of Mayer and Joule were received, what constituted the new theory in the period under study, and how it was supported experimentally. A connection was found between the new theory and thermodynamics which benefited both of them. Some considerations are offered about the desirability of taking a historical approach to teaching energy and its conservation.
\end{abstract}

\section{Introduction}

\subsection{Some Problems in Teaching Energy}

One of the stimuli for doing this research was a concern with some deficiencies in teaching energy and the principle of energy conservation (PEC). Students' various difficulties with the concept of energy and suggestions for overcoming them have been amply researched and debated in the last 30 years, as shown in recent surveys (Doménech et al. 2007; Coelho 2009; Papadouris and Constantinou 2011). Yet, one issue has not been directly addressed in the debate: a relationship between the generality and specificity in the formulation and usage of PEC.

The current practice is to start the unit on energy with definitions of mechanical energy of a body in its kinetic and potential forms and formulation of the principle of conservation of the total mechanical energy, which sounds like this:

When energy is transferred between objects in an isolated system, the total energy of all the objects after the change is the same as the total energy of all the objects before the change. (Breithaupt 2003, p. 52).

Immediately after that this principle is generalized so that the 'total' means a sum of all kinds of energy in the system of bodies. Sometimes this general principle of energy conservation (GPEC) comes in a slightly different form:

N. Kipnis $(\bowtie)$

Independent scholar, Minneapolis, USA

e-mail: nahumk@gmail.com 
Energy may be transformed from one kind to another, but it cannot be created or destroyed, the total energy is constant (Halliday and Resnick 1978, p.151)

Armed with this general definition, students are expected to apply the concept of energy conservation to various phenomena. In this students face several difficulties. One is an uncertainty about the meaning of energy. Usually, textbooks follow Maxwell's definition:

(T)he energy of a body may be defined as the capacity which it has of doing work, and is measured by the quantity of work which it can do. (Maxwell 1871, p. 90)

Some educators criticized this definition as inapplicable to thermodynamics and recommended replacing 'work' with 'change' or another word, or avoiding a general definition of energy altogether, offering instead equations for specific kinds of energy. ${ }^{1}$

However, specifics kinds of energy are expressed in units of work, and deriving an energy equation for a particular phenomenon is based on work too. These facts mean skipping the general definition through work is meaningless. The same comment is true for Bunge's definition of energy as 'a universal property of matter' (Bunge 2000, p. 461). However universal philosophically, energy still needs to be expressed in units of work, even in such science as sociology.

To a physicist, lack of a rigorous definition is not a major obstacle for doing research. $\mathrm{He} / \mathrm{she}$ treats the energy of a system as a certain number which depends on the system's conditions. For instance, a charged condenser possesses an energy that depends on its capacitance and the potential difference between its electrodes. If we connect the electrodes with a wire, electrostatic energy disappears, but the wire releases a certain amount of heat. A ratio of the numbers characterizing electrostatic energy in the condenser and the quantity of heat in the wire is a constant: this is how a physicist views energy conservation and transformation.

However, to some teachers the concept of 'energy-as-number' is too abstract, especially for younger students. They favor a less scientific definition, in which energy would resemble a substance, which can be spoken of as 'stored', 'transferred', 'consumed', etc. Naturally, such an approach provokes objections, for a number cannot be 'created' or 'transformed', etc. ${ }^{2}$ This subject deserves a discussion which may be useful even for highschool physics teachers, because, as shown above, this language enters the definition of the principle of energy conservation, which they certainly need to teach. Yet, I reserve a discussion of feasibility of modeling energy by a substance for the next part when we will know more about GPEC.

A suggestion that caught my attention was,

to consider at first some very restricted area -simple mechanics or perhaps currents - investigate concepts of work, energy and energy conservation, and only then, having this background firmly established, take the bold leap to generalize energy to all other phenomena. (Brojan 1983, pp. 204-205, italics added)

This reminded me how I myself used to teach energy: first, in mechanics, next in heat phenomena, and only then I gave the definition of GPEC. Searching for arguments to support such a case I turned to the history of science to see how the concept of energy conservation actually evolved: sometimes knowing the details of its discovery helps to understand the concept.

\footnotetext{
1 See, for example, Lehrman (1973), Iona (1973), Hicks (1983), Kemp (1984), Trumper (1990), Walker (2007), and Hecht (2007).

2 Among proponents and opponents, Sexl (1981, Warren (1982), Watts (1983), Solomon (1984), Coelho (2009, 2013), Lancor (2012), Rizaki and Kokkotas (2009)
} 


\subsection{Historiographical Remarks}

Finding proper historical materials turned out difficult, for, although historiography of GPEC is vast, ${ }^{3}$ it does not offer much regarding the process of this discovery since 1847. At first historians focused on priority issues, ${ }^{4}$ then or logical schemes of how the various old scientific and philosophical concepts should (or could) have evolved with time into the concept of energy. ${ }^{5}$ Thomas Kuhn shifted the discussion to individual contributors and their motivations (Kuhn 1959). He treated the discovery as a case of a simultaneous discovery between 1830 and 1850 by twelve individuals listed in three groups. The first comprised of Robert Julius Mayer (1814-1878), James Prescott Joule (1784-1858), Ludwig A. Colding (1825-1888), and Hermann von Helmholtz (1821-1894). The second group included Nicolas Léonard Sadi Carnot (1796-1832), Marc Séguin ainé (1786-1875), Carl von Holtzmann (1815-1875), and Gustave Adolphe Hirn (1815-1890). Finally, the third group consisted of Carl Friedrich Mohr (1806-1879), William Grove (1811-1896), Justus von Liebig (1803-1873), and Michael Faraday (1791-1867) (ibid., p. 321). ${ }^{6}$

To explain why the discovery took place between 1830 and 1850 and not at another time, he supposed presence of several factors which were 'in the air' at that time but not earlier, in particular, an availability of many conversion processes, a concern with engines, and a particular philosophy of nature called Naturphilosophie. A number of scholars adopted this approach of collective discovery, although they differed from Kuhn in some details (trigger-factors, some pioneers, etc.). ${ }^{7}$ Most of them focused on researching contributions of single individual. ${ }^{8}$ Those few who considered groups of pioneers in general followed Kuhn's line, although they offered some innovations. Thus, Muriel Guedj added to Kuhn's list Clapeyron, Thomson, and Clausius (Guedj 2000), and Norbert Schirra selected from a preliminary group of 12 candidates (the same group as Kuhn's except for Clapeyron replacing Hirn) four 'discoverers': Mayer, Joule, Colding, and Helmholtz (Schirra 1991, pp. 155-57). Possibly, he meant that 'discoverers' were entitled to more credit than mere 'contributors'.

Naturally, the selection depends on the definition of discovery. Apparently, Schirra views energy PEC as a mathematical concepts, because his criteria for selecting 'discoverers' were quantification of energy concept and obtaining a numerical relation between different forms of energy. Kuhn's criteria are different:

\footnotetext{
Between 1842 and 1847, the hypothesis of energy conservation was publicly announced by four widely scattered European scientists-Mayer, Joule, Colding, and Helmholtz-all but the last working in complete ignorance of the others. The coincidence is conspicuous, yet these four announcements are unique only in combining generality of formulation with concrete quantitative applications. Sadi Carnot, before 1832, Marc Séguin in 1839, Karl Holtzmann in 1845, and G. A. Hirn in 1854, all recorded their independent convictions that heat and work are quantita-tively interchangeable, and all computed a value for the conversion coefficient or an equivalent. The
}

\footnotetext{
3 See, for example, bibliography compiled by Crosbie Smith (Smith 1998, pp. 356-385). It contains both secondary and primary sources.

${ }^{4}$ See, for instance, Tyndall $(1862,1863,1864)$, Tait $(1863,1864)$, Tait (1887), Verdet (1868, pp. XCVICXII).

5 See, for example, Helm (1887), Haas (1909), and Mach (1911/1872).

6 R. Garcia (1987, pp. 136-140) offered to add to this list Thomson and Clausius, but his arguments are too brief to be useful.

7 See, for instance, Boyer (1959, p. 390), Hiebert (1959, pp. 394-96); Heimann (1973), M. Guedj (2000).

8 Among them, Caneva (1993), Cotté (2002), Elkana (1974), Hutchison (1981), Lervig (1972), Mendoza (1959), Steffens (1979), Yagi (1984), and others.
} 
convertibility of heat and work is, of course, only a special case of energy conservation, but the generality lacking in this second group of announcements occurs elsewhere in the litera-ture of the period. Between 1837 and 1844, C. F. Mohr, William Grove, Faraday, and Liebig, all described the world of phenomena as manifesting but a single "force," one which could appear in electrical thermal, dy-namical, and many other forms, but which could never, in all its transformations, be created or destroyed. (Kuhn 1959, p. 321, italics added)

Thus, in Kuhn's view, the complete set of contributions to the discovery of 'hypothesis of energy conservation' consisted of a general formulation and specific quantitative applications. Apparently, 'convertibility of heat and work' comes under the category of 'applications'. As to the general formulation, in Kuhn's view, it was a statement about the existence of a 'force' which can appear in different forms but cannot be either created or destroyed. The problem with this formulation is that it looks purely qualitative, mathematics is reserved only for applications.

We see that Schirra's 'discoverers' coincide with Kuhn's first group which contributed the most and therefore got the greatest credit. Unless Schirra refuses other eight contributors any credit at all, his innovation offers nothing new.

\subsection{Setting the Problem}

Kuhn's purpose was to establish group motivational factors that prompted the pioneers to do their research at a particular time. He described the discovery as a rapid and often disorderly emergence of the experimental and conceptual elements from which that theory [PEC] was shortly to be compounded' (Kuhn 1959, p. 323, italics added).

Several questions were of great interest to this author. What did 'shortly' mean: 5 years? 10 years? Did Kuhn's upper boundary of the time period he selected-from 1830 to 1850 - mean that the discovery was completed by 1850 ?

Also, how was this 'compounding' done? Kuhn hints that this could have been done on the basis of the 'concept of the universal convertibility of natural powers', which led to the 'notion of conservation' by 'small and rather obvious' steps. In his view, these steps consisted of applying 'equality of cause and effect or the impossibility of perpetual motion' (Kuhn 1959, p. 328, italics added).

Finally, who was supposed to do it? Did Kuhn mean his 12 pioneers? There are no hints about any outsiders.

Whether Kuhn knew answers to these questions or not, they were left for others to discover. And since no such attempts had been done earlier, there was no choice for this author than to do it himself. The following initial formulation of the problem sounded quite plausible: What was the actual process of establishing PEC? The main question include others, such as: What was the sequence of events? Did the process start with the general formulation of GPEC or with its particular applications? Who was truly influential in the process?

To outline the plan of this paper I have no choice but to use now the finding discussed further. It will be shown that the process of discovery of energy conservation began with a particular case of heat/mechanical work transformation. Accordingly, this paper, which serves as Part I of a three-part research, will study the development and role of MEH. Part II will show how the general concept of energy conservation evolved from applications of MEH to other phenomena, and Part III will deal with the role of vibration theory of heat in creating and promoting GPEC. In particular, it will address the date of the discovery. Pedagogical questions will be discussed in both Part II and Part III. 


\subsection{Methodology}

To start answering questions set above we need to find whom to ask. This means asking historical personae their opinions about the discoverers. Kuhn claimed that this is what he did to select the pioneers:

I have tried to include all the men who were thought by their contemporaries or immediate successors to have reached independently some significant part of energy conservation. To this group I have added Carnot and Hirn whose work would surely have been so regarded if it had been known. Their lack of actual influence is irrelevant from the viewpoint of this investigation (Kuhn 1959, p. 343 , italics added)

There are two circumstances which might make using some results of Kuhn's selection unsuitable for this research. One is that we do not know how many sources Kuhn consulted about each pioneer, and how selective he was in choosing the sources. Another is his deliberate neglect of the factor of influence, displayed at least in the cases of Carnot and Hirn: he selected them although the works for which they were selected were unknown before 1850. In particular, Carnot was chosen for his adoption of the dynamical theory of heat and obtaining mechanical equivalent of heat similar to that of Mayer. These facts became public knowledge only in 1878 (H. Carnot 1878). ${ }^{9}$

Thus, we may start with Kuhn's list but be ready to enter changes if the new information would warrant this.

To get data less prone to subjectivity and chance, the author examined about 200 papers and books on topics relevant to PEC and published within three decades since the first communications of Mayer and Joule. Papers were taken from scientific journals published in English, French, and German. The selection was guided by the bibliographies compiled by Jules Violle (1841-1923), Max Planck(1858-1947), and others (Violle 1872, Planck 1887). The idea was to find out which ideas and personalities those researchers considered to be important and influential in this area.

The initial selection of the time period of 1840-1870 was tentative, pending the evaluation that a certain stage of PEC has been established during that period. With the results turned out positive, there was no need to change the period.

\section{Influential Ideas and People, 1840-1870}

The examination produced two listings. One included popular physical concepts of the time related to phenomena of heat. The other was a list of individuals whom researchers mentioned in their papers. It will be useful to note here that, unlike modern articles, papers of that period offered very few names, if any. Thus, the reader may be assured that the researchers mentioned only those predecessors or contemporaries whom they considered important or influential.

Several results of the survey are puzzling. For instance, by far the most popular concept of that time was 'mechanical equivalent of heat (MEH)'. Next in popularity was 'mechanical (or dynamical) theory of heat', which usually meant something different from the theory of the nature of heat, even if connected with it. For a comparison, 'energy' and 'energy conservation' were rarely used.

\footnotetext{
9 As shown further, both fully deserved their share of credit but for reasons different from Kuhn's. In case of Hirn, the date subsequent to 1850 is immaterial, because the whole timeline is now different from Kuhn's. As to Carnot, he receives credit for his 1824 book on thermodynamics which was known at the time.
} 
Table 1 Names cited

\begin{tabular}{|c|c|c|c|}
\hline Name & $1845-1850(25)$ & $1851-1861(61)$ & $1862-1872(38)$ \\
\hline Becquerel & 1 & 1 & 1 \\
\hline Bourget & 0 & 0 & 4 \\
\hline Carnot & $11(2)$ & $23(3)$ & $7(7-8)$ \\
\hline Clapeyron & $6(\mathbf{4 - 5})$ & $9(\mathbf{9 - 1 0})$ & 3 \\
\hline Clausius & 0 & $28(2)$ & $15(3-4)$ \\
\hline Colding & 0 & 0 & 4 \\
\hline Davy & $5(6-7)$ & 5 & 2 \\
\hline Delaroche \& Berard & 2 & 1 & 0 \\
\hline Dulong & 2 & 2 & 2 \\
\hline Faraday & 1 & 0 & 0 \\
\hline Favre & 0 & $9(\mathbf{9 - 1 0})$ & $8(\mathbf{5}-\mathbf{6})$ \\
\hline Gay-Lussac & 1 & 1 & 2 \\
\hline Grove & 2 & 0 & 0 \\
\hline Helmholtz & 1 & $11(7-8)$ & $6(9)$ \\
\hline Hirn & 0 & 1 & 1 \\
\hline Holtzmann & $6(4-5)$ & 3 & 1 \\
\hline Joule & $14(\mathbf{1})$ & $42(\mathbf{1})$ & $18(\mathbf{1})$ \\
\hline Liebig & 2 & 2 & 0 \\
\hline Mayer & $8(3)$ & $13(6)$ & $15(\mathbf{3}-\mathbf{4})$ \\
\hline Matteucci & $3(\mathbf{9}-10)$ & 0 & 0 \\
\hline Person & $3(\mathbf{9}-10)$ & 3 & 0 \\
\hline Regnault & 2 & $17(5)$ & $8(\mathbf{5}-\mathbf{6})$ \\
\hline Rankine & 0 & $11(7-8)$ & $8(\mathbf{5}-\mathbf{6})$ \\
\hline Reech & 0 & 1 & 1 \\
\hline Rumford & $5(6-7)$ & 0 & 2 \\
\hline Séguin & $4(8)$ & 0 & $7(7-8)$ \\
\hline Thomson, W. & 2 & $20(4)$ & $16(2)$ \\
\hline
\end{tabular}

The list of names also provided a few surprises, the greatest of which was a prominent presence of people who were not supposed to be there at all, namely, Carnot, Clapeyron, and Holtzmann who are known for their contribution to thermodynamics but not PEC (Table 1). In this table the number against a person means the number of articles which cited his name, the number in parenthesis being his ranking for the given time period, and the number by the date is the total number of articles for this period.

That it was thermodynamics and not their other works which placed the triad on the list is obvious, because Carnot published only one work, and it was a book on thermodynamics.

These results provoke several questions three of which will be our major preoccupation:

1. Why did researchers consider the thermodynamics in general, and the old one in particular, so relevant to PEC between 1840 and 1870 ?

2. Why was the mechanical equivalent of heat (MEH) so important at the time?

3. What was the meaning of the mechanical theory of heat (MTH) and what was its connection, if any, with MEH? 
We will start unraveling the three puzzles with thermodynamics, which precedes both MEH and MTH.

\section{The Early Thermodynamics: From 1824 till 1840}

\subsection{Carnot}

Thermodynamics was a new science founded in 1824 by Nicolas-Léonard-Sadi Carnot (1796-1832). Sadi Carnot was a son of the famous Lazare Carnot (1753-1823), who distinguished himself as a mathematician, a politician, and as a general. Sadi was trained as a military engineer, but the exile of his father precluded Sadi from a successful military career, and he devoted much of his time to studying science.

In 1824, he published the results of his research in a small book Reflections on the Motive Power of Heat (Carnot 1978/1824). The early thermodynamics, naturally, did not include PEC, nonetheless, it was able to produce several important results.

Carnot saw thermodynamics as a general theory of heat engine. At that time, engineers had offered a variety of ways to improve steam engines, such as replacing water vapors with those of other liquids, or with a gas, using steam of high pressure, and others (Birckbeck and Adcock 1827). They made theories specific to certain types of engines and based on empirical data. In particular, they offered a number of empirical equations for calculating heat of evaporation, or pressure of vapors of different substances as functions of temperature, and others.

A routine method to estimate the efficiency of an engine was a calculation of the amount of work obtained per unit of steam produced in the engine. If we recalculate this number per unit of heat, it would look as an experimentally obtained MEH. We should remember, however, that having been interested only in relative numbers, the engineers normally did not take precautions scientists do, thus, we should not compare their results with those of Joule and other experimenters.

Unlike engineers in the field, Carnot focused on general results applicable to all heat engines. In particular, he tried to prove the existence of a limit for mechanical work obtained in a heat engine and he wanted to calculate this maximal MEH theoretically.

To achieve this goal Carnot considered an ideal heat engine that used a reversible process of steam (or gas) expansion and compression. This process, later called the Carnot cycle, consisted of isothermal and adiabatic expansions and compressions which returned steam (or gas) into the original conditions respecting its pressure, volume, and temperature at the end of each cycle. In Carnot's view, steam (or gas) absorbed heat from the boiler and expanded, producing work, and at the end of expansion gave away heat to a cold condenser. He thought that mechanical work resulted from the mere fact of heat transferbetween boiler and condenser-but not from its consumption. To bring back the steam to its original condition respecting volume, pressure, and temperature, in the reverse part of the cycle the steam was to be compressed by an external force.

Carnot also assumed that at the end of the cycle the steam will also regain the initial amount of heat. Clausius abandoned this fundamental hypothesis in 1850 as false, but in the meantime it did not prevent Carnot and others from obtaining by its means a number of valuable results. In particular, Carnot deduced, by relying on the impossibility of the perpetuum mobile, that the maximal mechanical work produced in his cycle could not be increased by any other process, and that it did not depend on the working body (gas or 
vapors). The consequence of this discovery was a possibility to apply to steam well known gas laws such as the laws of Boyle-Mariotte and of Dalton-Gay-Lussac.

Among Carnot's contributions were several new laws for gases. One was that the motive power of heat depended on the difference of temperatures of the hot and cold bodies. Another was that the difference of specific heats at a constant pressure and at a constant volume was the same for all gases. In particular, Carnot supposed that the quantity of heat transferred during the cycle was proportional to temperature difference between the hot a cold bodies. On the basis of this equation he calculated the amount of work produced by a transfer of a unit of heat. However, this MEH was too low compared to what became later known the correct one, and probably for this reason Carnot had never been any credit for the first determination of MEH ("Appendix 1")..$^{10}$

After his book was published, Carnot changed his method of computation and obtained a new result of $370 \mathrm{kGm} / \mathrm{kcal}$. However, this became known only in 1878 (Carnot, $\mathrm{H}$. Carnot 1878, p. 969). Apparently, the new method of calculations was connected to his adoption of the vibratory theory of heat which did not require conservation of heat during the cycle ("Appendix 1").

\subsection{Clapeyron}

Carnot's work was largely ignored until Émile Clapeyron (1799-1864) discovered it and somewhat improved (Clapeyron 1834). A civil engineer by training and a good mathematician, Clapeyron became involved since 1830 in locomotive construction and design of steam engines. Probably this engagement drew him to Carnot's book.

Clapeyron gave Carnot's ideas a more elegant mathematical expression, in particular, by adding a graphical interpretation of Carnot's cycle, which made more clear the calculation of work produced during a cycle. Like Carnot, Clapeyron assumed that the quantity of heat transferred by gas depended only on temperature. In calculating the quantity of heat involved in the cycle, he widely used a combination of Boyle-Mariotte's and Gay-Lussac's laws into what later became known as the equation of an ideal gas. He also successfully applied to vapors the equation he deduced for gases to establish a relation between latent heat, the volume of vapors, and their pressure ("Appendix 2"). This equation eventually acquired Clapeyron's name.

Clapeyron's assumptions about the method of calculating MEH were similar to those of Carnot, and the result turned out to be similar to Carnot's (ibid.).

\section{The Revival of Thermodynamics, the 1840s}

\subsection{Steam Engine}

It took a decade until Clapeyron's paper found readers who could benefit from it, and thermodynamics came to the forefront of science. The reason turned out the same as the one which stimulated the creation thermodynamics in the first place: steam engine.

\footnotetext{
10 This paper uses the units popular at the time in Continental Europe: kGm for work, and kcal for a quantity of heat. A force of $1 \mathrm{kG}(9.8 \mathrm{~N})$ acting at the distance $1 \mathrm{~m}$ produces the work of $1 \mathrm{kGm}$. Thus, 1 $\mathrm{kGm}=9.8 \mathrm{~J} .1 \mathrm{kcal}$ is the quantity of heat required to raise the temperature of $1 \mathrm{~kg}$ mass of water by $1^{\circ} \mathrm{C}$. Carnot's result was $1.4 \mathrm{kGm} / \mathrm{kcal}$, while a correct one is $426.7 \mathrm{kGm} / \mathrm{kcal}$.
} 
It happened so that the 1830s was the time of a growing interest in steam engines among engineers and scientists. Clapeyron was already a part of this movement, which intensified even more after the publication of his treatise. More books appeared on steam engines and locomotives for engineers which discussed scientific foundations of the engine's work, including gas laws and empirical laws for saturated and unsaturated steam. Among them were the book by François Marie de Pambour (b. 1795), immediately translated into the English (Pambour 1839a, b), and another book, by Marc Séguin (Séguin 1839). The French governments supported experiments of Arago, Dulong, and Regnault which produced improved tables of the relations between pressure and temperature and others. The theoreticians, on their part, beginning with Carnot and Clapeyron, tended to complete their researches by applying the results to practical cases and using the tables produced by the experimenters.

In the 1840s, this trend affected several people who played, according to our survey, an important role in developing thermodynamics and/or PCE. They had an interest in mathematical treatment of the work of steam engines which was not easy to satisfy, because there were then only two treatises of this kind in existence. One was by Carnot (1824), and it was practically unavailable. The other was Clapeyron's (1834) paper which, being published in a journal, was still accessible, at least in Paris, and still fresh in memories. Thus, it was Clapeyron's paper that came to be disseminated to give thermodynamics a fresh start. To a considerable degree this happened through its translations. Its English translation appeared in 1837 (Clapeyron 1837) and the German, in 1843 (Clapeyron 1843).

The variety of available languages was very fortunate, because people interested in thermodynamics - some already familiar to us-were from three different countries. Séguin was French, Joule and William Thomson (1824-1907), from England, while Helmholtz, Holtzmann, and Rudolf Clausius (1822-1888) were from Germany. By 1845 , Joule, Holtzmann, Thomson and possibly Séguin, had already read Clapeyron's paper. Apparently, Thomson first read it in the original French, for at that time he spent several months in Paris at the laboratory of the chemist and physicist HenryVictor Regnault (1810-1878) who was probably the one who brought Clapeyron's paper to Thomson's attention.

\subsection{Séguin}

Marc Séguin (1786-1875) was a French engineer, inventor, and entrepreneur. He invented the wire-cable suspension bridge and the multi-tubular steam-engine boiler. Seguin's boiler enabled steam-engine trains to increase power and velocity from 4 to 25 miles per hour. He wrote books on application of mathematics and physics in engineering, especially building bridges and locomotive engines. He was elected to the Paris Academy of Sciences, and his name was inscribed on Eiffel Tower, among 72 names of the best French scientists and engineers, such as Lagrange, Le Verrier, Malus, Fresnel, Borda, Fourier, Carnot, Cauchy, Gay-Lussac, and others.

One of his books called 'On the influence of railroads' included a chapter about the usage of steam in a locomotive (Séguin 1839, pp. 378-397). He supposes an existence of a law connecting the movement produced with the quantity of heat involved, and which does not depend on the choice of steam or gas. Thus, he believes that the amount of work obtained from a machine is proportional to the difference of temperatures of the boiler and condenser. This reminds Carnot: either Séguin read Carnot (or Clapeyron), or he came up with these ideas on his own. Another point of resemblance is his usage of the perpetuum mobile argument. Séguin argues that if the whole amount of heat carried by the steam 
during its expansion is transferred to the condenser, by collecting this heat from water in the condenser and using it to produce steam, one would be able to repeat this cycle indefinitely, which means that,

Thus, one could have obtained an indefinite quantity of motion by means of a finite mass of caloric, but neither common sense nor sane logic can admit this.

However, since the currently accepted theory leads to this result, it appears to me more natural to suppose that a certain amount of caloric disappears in the very act of producing force or mechanical power. (ibid., p. 382, italics added)

Séguin tried to show experimentally that steam gives away to condenser less heat than it receives from the boiler, but the results were not decisive. To show how difficult such experiment were, it is enough to mention that it took more than 15 years until Hirn succeeded with this experiment.

Since Séguin's statement implied convertibility of heat into mechanical work, science could have gained three years if it were read. Unfortunately, physicists did not read Séguin's book, and it did not occur to the author to publish his hypothesis separately. Or, more probably, he avoided publishing it because it had no experimental support. Yet, merely 3 years later he could have witnessed that some others had different ideas of hypotheses. The person in question was Julius Robert Mayer (1814-1878).

\subsection{Mayer and the Principle of Convertibility}

A son of a pharmacist in Heilbronn, Germany Mayer developed an interest in medicine and studied it at the University of Tübingen. After receiving his medical diploma in 1838, he became a ship doctor and sailed with the ship to Java. During this trip he observed that venous blood in tropics in the tropics was of a much brighter red color than in the northern parts, which set his mind on thinking about the nature of heat and its transformations. After his return in 1841, Mayer settled in Heilbronn, started a family and wrote his first article 'Remarks on the forces of inorganic nature' which he published in 1842 in Liebig's journal Annalen der Chemie und Pharmacie (Mayer 1842).

Although the journal was well known, no one paid attention to Mayer's article, and Séguin had to wait for five more years for another occasion to learn that his idea was rediscovered by another scientist. Apparently, one of the reasons for this neglect was Mayer's peculiar style: his arguments were brief, short on experiments but abundant of hypotheses and metaphysical terms. The essence of his argument, as understood later, was that when motion appeared to vanish, for instance, in rubbing two bodies together, it was in fact transformed into heat. To Mayer, both motion and heat were 'forces' which were indestructible but convertible into one another. His other way of looking on such a transformation was that of a cause and effect:

we prefer the assumption that heat proceeds from motion, to the assumption of a cause without effect and of an effect without a cause. (Mayer 1865, p. 256; 1842, p. 238)

Mayer recognized that like vanishing motion when rubbing is stopped produces heat, 'so does heat disappear as a cause when its effects are produced in the shape of motion, expansion, or raising of weight' (Mayer 1865, p. 257).

This statement eventually acquired the name of the 'principle of convertibility'. Mayer also stated that there was a numerical relation between work and heat such that warming a certain mass of water by $1{ }^{\circ} \mathrm{C}$ corresponded to the fall of this mass from the height of $365 \mathrm{~m}$. The derivation of this number appeared only in 1845 ("Appendix 2"), in a pamphlet which few people read at the time (Mayer 1867, pp. 28-30). 
While Mayer might have convinced himself that the numerical equality of the two forces necessarily followed from an application of the metaphysical notion 'cause equals effect', its demonstrability to others was questionable. Here is what his contemporary Hirn said on this subject

The idea of the existence of proportionality between the cause and the effect comes to us naturally. If in a steam-engine, for example, it is heat which creates work, it is very clear that the received quantity of one must be in direct relation with the quantity dispensed by the other. It seems, therefore, that ...to do any experimental verification is useless. However, ... if the existence of the principle itself has never been seriously challenged, it is not so about ... its realization in experiment. Many physicists appear to believe that due to additional circumstances, unavoidable in phenomena, the proportionality may break completely, and they believe that the question of heat engines... is too complicated to be resolved by a simple law of the definite relation. (Hirn 1865, p. 30, italics added) ${ }^{11}$

With Mayer's paper waiting for readers, the relation between heat and work was attacked by James Joule, an English brewer by profession and a scientist by vocation.

\subsection{Joule and the 'Mechanical Equivalent of Heat'}

James Prescott Joule (1818-1889) was taught by private tutors, and his interest in scientific matters came from practical needs: he was thinking of replacing s steam engine at his brewery with a recently invented electrical motor run by a battery. Among other things this required calculating whether the expenditure on zinc in the battery was lesser that that on coal, for the same amount of work produced. This required measuring work produced by an electric motor and comparing it with losses on heat in the circuit and the consumption of zinc. Thus, his early interests in science were with electrical motors and batteries. To measure losses he had to determine how the amount of heat produced by a current depended on the current and resistance in the circuit. This research won Joule some distinction.

While considering induction current as a source of heat, Joule realized that unlike galvanic current, the heat it produced was not transferred from one part of the circuit to another but was generated on the spot. This contradicted the dominating theory of heat as an imponderable fluid that can move from one body to another and whose total amount is constant. A generation of heat contradicted this constancy. Further experiments proved that the heat produced by induction current obeys the same law as heat created by a voltaic battery (Joule 1843).

At some point, Joule decided to compare the amount of heat produced by induction current with the work spent to rotate an electromagnet. He concluded that the relation between them, which he initially called the 'mechanical value of heat' was (in continental units, as shown above) $460 \mathrm{kGm} / \mathrm{kcal}$. Joule emphasized the fact that 'heat... may be converted into... a mechanical force' (ibid., p. 441, italics added). That was the principle of convertibility reinvented. Two years later he replaced 'mechanical value of heat' with 'mechanical equivalent of heat' which was universally adopted since (Joule 1845a, p. 369).

As we will see further, among more reliable results, the first Joule's MEH $=460 \mathrm{kGm} /$ kcal was too high, while that of Mayer, $365 \mathrm{kGm} / \mathrm{kcal}$, was too low. ${ }^{12}$

Joule himself knew about lack of precision of his first MEH experiment. Later Rankine suggested that its cause was an abundance of energy transformations in this experiments

\footnotetext{
11 See how proportionality can be violated in a heat engine in the discussion of Ewart's paper in Sect. 8.

12 Since we will use only one unit of $\mathrm{MEH}, \mathrm{kGm} / \mathrm{kcal}$, subsequently the numbers will appear with units omitted, as, for instance, $\mathrm{MEH}=365$.
} 
(see Rankine's comment in Sect. 8). For this reason alone, this experiment should not have been selected here for a discussion. Yet, there was also another, even stronger, reason to skip it: the author's contention that MEH could have been properly determined at the time (and demonstrated now) merely by means of heat/mechanical transformations. While historically many such experiments were contemporaneous with phenomena where heat was produced by electricity, magnetism, and other phenomena, the legitimacy of the latter was based on the assumption that PEC is valid for all phenomena, which had not been sufficiently proven for a while. Thus, the selection of Joule's (1843) experiment is rather symbolic, merely as of the first experiment for determining MEH.

Since 1845, the term 'mechanical equivalent of heat' appeared in many articles, usually meaning a number without an explicit association with any theory. Yet, many physicists agreed that the theory behind MEH was the principle of convertibility. Thus, unless specified otherwise, every further mention of MEH will imply its connection with the principle of convertibility, and every reference to convertibility will mean its association with a constant number.

In fact, the first part of this statement is exaggerated, for there was a different interpretation of $\mathrm{MEH}$, which appeared soon after the first, and whose author was Holtzmann.

\subsection{Holtzmann}

Carl von Holtzmann (1815-1875) was at the time a teacher of mathematics and physics at Mannheim Lyceum. He read Clapeyron in German and developed his ideas on this subject in a paper 'On the heat and elasticity of gases and vapors' which he published in a pamphlet in Mannheim in 1845 (Holtzmann 1846).

Holtzmann upheld Carnot's hypothesis of conservation of heat during the cycle. His purpose was to improve Clapeyron's theory by specifying the magnitude $\mathrm{C}$ which Clapeyron left undetermined (Holtzmann called it $\mathrm{F}_{\mathrm{t}}$, like Carnot). To achieve this he assumed that the amount of work creating heat was always proportional to the quantity of heat produced. He even announced that this proportionality can be used to measure heat in units of work, which is exactly what we do today (ibid., p. 192). Naturally, for this procedure to work, the coefficient of proportionality had to be constant. With this assumption he simplified the function $\mathrm{F}_{\mathrm{t}}$ ("Appendix 3").

Note that Holtzmann did not say anything about motion and heat being converted into one another. In fact, he opposed to such an idea. His principle of proportionality (or equivalence) produced the same numerical results as that of convertibility, because the coefficient of proportionality (MEH) was the same, but their physical meaning was different.

Helmholtz objected to Holtzmann's procedure that,

This method of calculation... is only admissible when the entire vis viva of the heat communicated is actually returned as mechanical force, hence the sum of the vis viva and tensions, that is, the quantity of free and of latent heat, is just the same in the more expanded gases as in the denser ones of the same temperature. (Helmholtz 1853, p. 136-37)

This critique, was, of course, generic. It was applicable to any theoretical consideration of this matter, for it was impossible to predict theoretically, without conducting many experiments, whether a particular expansion of a gas leaves its essential inner conditions intact. Perhaps Helmholtz realized that this criticism was not very fair, for he found it necessary to emphasize merits of Holtzmann's work: 
In support of the correctness of Holtzmann's law, a great number of consequences from it which agree with experiment might be adduced; more particularly the deduction of the formula for the elasticity of the vapours of water at different temperatures. (Helmholtz 1853, p. 137)

Holtzmann's procedure for calculating MEH was in part similar to Clapeyron's and in part to Mayer's, and his result-374 kGm/kcal—was very close to Mayer's ("Appendix 3"). Apparently Holtzmann acted independently, for it was very unlikely that he read Mayer's (1845) pamphlet published in a different city at the same time as his own. It is puzzling that, in Holtzmann's view, 'Clapeyron obtained the same result, but gave it in more complicated numbers'. ${ }^{13}$ (Holtzmann 1845, p.196, italics added)

\section{Mechanical Theory of Heat and Thermodynamics: The 1850s}

\subsection{What is Mechanical Theory of Heat?}

Unlike mechanical equivalent of heat, the term 'mechanical (or dynamical) theory of heat' appeared comparatively late. We should not confuse this term with a similar one which refers to the nature of heat. The mechanical theory of heat in that meaning was also known as 'dynamical', 'vibratory', or 'wave theory', of which we will use in this research the latter two to avoid any confusion. We will explore the role of vibratory theories of heat in detail in Part III.

Apparently it was Victor Regnault who introduced the term mechanical theory of heat (MTH) in 1853 (Regnault 1853). While reviewing existing theories dealing with heat and work he began with Carnot's principle that the work produced by a heat engine was due to a passage of heat from a hot body to colder one, then proceeded with Clapeyron's hypothesis that the quantity of heat gained or lost by the same gas depended not only of its initial and final states but also on intermediary states between these two after which he noted that,

The mechanical theory of heat is again in favor after several years, and at this moment it preoccupies a great number of geometers. However, Carnot's principle has undergone an important modification by admitting that heat can be transformed into mechanical work and the mechanical work can be transformed into heat. (ibid., pp. 677-78, italics added)

What Regnault is saying here is that the mechanical theory of heat had existed earlier, was forgotten for a while, and is being now revived. It is clear that in this context 'Carnot principle' means the same as mechanical theory of heat. Thus, to Regnault, mechanical theory of heat coincided, at least in part, with thermodynamics. In 1862, Émile Verdet formulated this explicitly:

We give the name mechanical theory of heat, or sometimes thermodynamics, to the science that studies mechanical effects due to heat and heat produced by mechanical agents. (Verdet 1868, p. XII, italics added)

While Mayer probably had no idea that his derivation of MEH was thermodynamic, repeating ideas of Carnot and Clapeyron, others did think so. Peter Tait (1831-1901), for instance, described the field of Mayer's initial research as 'thermodynamics' (Tait 1864, p. 289).

\footnotetext{
${ }^{13}$ The German original is not available, but an abridgement of this article in the Annalen der Physik gives this obscure expression as weniger übersichtlichen Zahlen, or 'not very transparent numbers' which does not help much. If Holtzmann meant that Clapeyron obtained MEH near 370, this author has not yet discovered it. Perhaps he meant something different.
} 
Since some physicists admitted in their papers on thermodynamics some influence on their research of their views on the nature of heat, there may be doubts when such views were not explicitly revealed, whether they were essential to the appearance of new laws and principles in the 1850s. The following Hirn's definition of mechanical theory of heat may clarify the situation:

A doctrine which, independently of all hypotheses on the nature of heat, attaches all the effects, static and dynamic, to most elementary principles of mechanics, and transforms them into mathematical formulae. (Hirn 1865, p. 2)

This attitude towards laws and methods of thermodynamics as independent of the views on the nature of heat, became a hallmark of this science. Gabriel Lippman (1845-1921), a Nobel laureate, defined thermodynamics as:

Thermodynamics is a part of physics which studies relations between the mechanical work, on one side, and the quantity of heat and temperature, on the other, independently of all hypotheses on the nature of heat.

It is rested on two general laws based on experiment called the Principle of Equivalence and the Principle of Carnot.(Lippman 1889, p. 1, italics added).

Placing the name of Carnot in the definition emphasizes the continuity between the old and the new thermodynamics.

Note that the independence stated by Lippmann has nothing to do with how the laws and methods of thermodynamics were actually discovered. Some discoverers did benefit from relying on a certain idea of the nature of heat (Carnot and Rankine are obvious examples), and we will talk more about this in Part III. However, once discovered, these laws and methods were used independently of any views on heat itself.

Now, one puzzle is solved: if the mechanical theory of heat is thermodynamics, then the popularity in our survey of the names of Carnot and Clapeyron, founders of thermodynamics, is very understandable. What remains uncertain why Carnot and Clapeyron appear alongside scientists unknown for their role in creating PEC, such as Clausius, Rankine, and Thomson. We need to have a look at their contributions.

\subsection{The Beginning of the New Thermodynamics}

In the passage quoted above, Regnault explained why Carnot and Clapeyron share the fame in our survey with the pioneers of PEC:

Joule, Thomson and Rankine in England, Mayer and Clausius in Germany, often departing from different points of view, have developed by calculations this mechanical theory of heat. (Regnault 1853 , p. 679 , italics added)

(The German translator of Regnault's article also added the name of Holtzmann.) Concerning Mayer and Joule 'developed by calculations' probably means quantitative research, which involves both ideas and experiments. Reech was more specific:

Joule, Thomson, Rankine, Mayer, and Clausius took upon themselves the work of correcting what was inexact in the relations established by Carnot and Clapeyron'. (Reech 1853, p. 357, italics added)

On these lists, Mayer, Joule, Thomson, Rankine, and Clausius appear as fathers of the new (post-1850) thermodynamics, but neither Mayer nor Joule did any theoretical work in this area. To understand the situation better, let us review, very briefly, the beginning of this new thermodynamics looking for connections with PEC. The story began with Thomson's reluctance to take the step which later made him famous. 


\subsection{Thomson}

William Thomson (1824-1907) graduated from Cambridge in 1845 as a Second Wrangler and winner of Smith Prize and went to work for several months in the laboratory of Victor Regnault. Apparently Regnault brought Clapeyron's paper to his attention. ${ }^{14}$ Thomson was impressed with Carnot's theory and decided to promote it and develop further. In 1848 when Thomson was already Professor of Natural Philosophy at the University of Glasgow, he offered an absolute scale of temperature based on Carnot's theory (Thomson 1848). Next year, he published a paper that popularized Carnot's theory and offered his own contribution to it (Thomson 1849).

Being well aware that the results of Joule's experiments were incompatible with the material theory of heat, Thomson faced the same dilemma as did Carnot 25 years earlier who noted then about keeping the hypothesis of conservation of the quantity of heat:

It may be remarked, in passim, that the fundamental principles on which the theory of heat rests should be given the most careful examination. Several experimental facts seem to be almost inexplicable in the actual state of that theory. (Carnot 1899, p. 20)

Finally, Carnot decided that retaining the hypothesis would serve his main purpose well and left his doubts aside. Yet, after the book was published these doubt led him to the mechanical theory of heat.

When Thomson had to decide which hypothesis to adopt, his thinking was similar to that of Carnot:

It might appear, that the difficulty would be entirely avoided, by abandoning Carnot's fundamental axiom; a view which is strongly urged by Mr. Joule ... If we do so, however, we meet with innumerable other difficulties - insuperable without farther experimental investigation, and an entire reconstruction of the theory of heat, from its foundation. (Thomson 1849, p. 545n, italics added)

To avoid those other difficulties and knowing that Carnot's hypothesis did produce some good results, Thomson decided to retain it. He somewhat modified Clapeyron's mathematics and chose a different way of calculating work produced by a transfer of a unit of heat. Instead of using a relation between specific heat at constant pressure and that at a constant volume, he introduced a function of temperature $\mu$ such that an integral by temperature taken between temperatures of the hot and the cold bodies would represent work. For practical purposes the integral could be reduced to a sum of mean values of $\mu$ determined for small temperature intervals between the two extreme temperatures. In this way, Thomson calculated his function $\mu$ from experimental results of Regnault and showed the correctness of Carnot's statement that within the same intervals of temperature more work is obtained in the lower temperature range. Thomson further developed the tendency exhibited by Carnot and Clapeyron to connect the theory to practical work with steam engines, by analyzing some existing engines and calculating their mechanical output as a percentage of the theoretical maximum.

While Thomson vacillated about accepting Joule's results in specific cases but not in general (Thomson 1850), his paper prompted Clausius and Rankine to do just that and beat him in the race for the first incorporation of convertibility of heat and work into thermodynamics. Rankine read his paper on February 4, 1950, Clausius submitted his article 2 months later, while Thomson read his new paper only in March of 1851 . However, as it

\footnotetext{
${ }^{14}$ Having failed to find a single copy of Sadi Carnot's book in Paris bookstores, Thomson had to learn Carnot's theory from Clapeyron's paper. Apparently, later he did find a copy of Carnot's book, for he referred to some of its pages in his 1849 paper (Thomson 1849, pp. 542, 565, 570). On the development of Thomson's ideas at that period see Smith (1976).
} 
concerns their priority and influence, it was Clausius who won: his article in Annalen der Physik appeared in the spring of 1850, while Edinburgh Transactions were delayed till 1853. ${ }^{15}$ Fortunately, readers could have learned about Rankine's and Thomson's adoption of convertibility of heat and motion from other articles published in 1851-1852. ${ }^{16}$

\subsection{Clausius}

Apparently, it was Thomson's (1849) paper that switched attention of Rudolf Clausius (1822-1888), a freshly minted doctor of philosophy, from optics, the field of his dissertation, to thermodynamics. At that time he taught physics at a gymnasium in Berlin. Impressed by Thomson's paper, Clausius became deeply interested in Carnot's theory and turned to Clapeyron's paper (in German) for details. Unlike Thomson, he dared to take the challenge:

I do not imagine that the difficulties are so great as Thomson considers them to be; for although a certain alteration in our way of regarding the subject is necessary, still I find that this is in no case contradicted by proved fact. It is not even requisite to cast the theory of Carnot overboard; a thing difficult to be resolved upon, inasmuch as experience to a certain extent has shown a surprising coincidence therewith... On a nearer view of the case, we find that the new theory is opposed, not to the real fundamental principle of Carnot, but to the addition 'no heat is lost'. (Clausius 1851, p. 4)

Thus, Clausius emphasized the merits of Carnot's theory and its agreement with experiment and explained that his intention was not to offer an entirely new theory but merely to replace one of the hypotheses of the old theory (conservation of heat during the cycle) with a different hypothesis which he calls the 'principle of equivalence of heat and work':

In all cases where work is produced by heat, a quantity of heat proportional to the work done is expended; and inversely, by the expenditure of a like quantity of work, the same amount of heat may be produced.(ibid.)

In his first paper, Clausius introduced 'internal work' and 'external work' but not yet a conservation law based on these concepts. He accomplished this in 1854 by expressing the First Law as $Q=U+A W$, where $Q$ is the quantity of heat, $\mathrm{U}$ is a function of the internal state of a body, $W$ is external work and $A$ is the heat equivalent of work.

\subsection{Rankine}

William John Macquorn Rankine (1820-1872) was born in Edinburgh and studied there in Military and Naval Academy and at the University of Edinburgh but did not graduate. At 18 he began working as a railroad surveyor and invented a new technique for laying out railway curves. Fascinated with heat engines, he began with finding a relationship between maximum pressure of saturated vapor and temperature (Rankine 1849). In 1850 he read a paper on a theory of heat based on his hypothesis of molecular vortices (Rankine 1853a, b). The paper was published only in 1853, but some of Rankine's ideas became known in 1851 (Rankine 1851a, b). Among them was the idea of convertibility of heat and mechanical power', which, he believes, was proven by Joule's experiments (Rankine 1851b, p. 282).

The paper itself contained the first formulation of energy conservation in thermodynamics where energy is still named vis viva:

\footnotetext{
15 Clausius (1850), Rankine (1853a), Thomson (1853).

16 Among others, Rankine (1851a, b), Thomson (1852a, b), Verdet (1852d).
} 
According to the theory of this Essay, on the contrary, and to every conceivable theory which regards heat as a modification of motion, no mechanical power can be given out in the shape of expansion unless the quantity of heat emitted by the body in returning to its primitive temperature and volume is less than the quantity of heat originally received: the excess of the latter quantity above the former disappearing as heat, to appear as expansive power, so that the sum of the vis viva in those two forms continues unchanged.(Rankine 1853a, p, 164)

By the time this volume was printed Rankine offered a general principle of energy conservation, which we will discuss in Part II.

\subsection{What was the 'New Thermodynamics'?}

By placing Mayer and Joule alongside Clausius, Rankine, and Thomson, Regnault and Reech were actually saying that the new thermodynamics was nothing else but the old thermodynamics plus the concept of convertibility, discovered by Mayer and Joule.

Thus, its contemporaries saw the mechanical theory of heat as coinciding, at least to some extent, with the new thermodynamics, and the latter as consisting of two components: the old thermodynamics and the principle of convertibility. But where is the energy conservation embodied as the First Law of Thermodynamics?

In fact, the first papers of Clausius, Rankine, and Thomson written in 1850-1851 had nothing so well phrased as the First Law in modern physics textbooks: Clausius introduced it in 1854 (Clausius 1854). One may say that the First Law is merely a mathematical expression of the principle of convertibility: if two entities of different kinds are mutually convertible, one may add them in the same way as if they were of the same kind. In other words, it was the principle of convertibility that constituted the essence of the First Law of Thermodynamics. ${ }^{17}$

We have now completed one line of research which established connections between $\mathrm{MEH}$, mechanical theory of heat, and thermodynamics. What remains to investigate is the inner history of MEH, in particular, how well was this important concept established. The first question is about the origin of this concept: was it a consequence of some general idea or a primary concept?

\section{The Origin of MEH}

To determine the starting point of the process of discovery of PEC and ideas and events responsible for it I undertook an additional study of the papers in the period from 1840 to 1850. Its main purpose was to verify an idea implied in Kuhn's paper that the 'general formulation' conceptually preceded 'applications'. MEH was listed among the latter, and as to the former, Kuhn interpreted it as the existence of a single 'force' which can appear in different forms. He associated this idea with his third group (Grove, Liebig, Faraday, and Mohr). This study took into account any evidence that the relevant works of these pioneers from Kuhn's list were noticed during the decade in question. It included any comments, excerpts from papers, and translations. In addition to these pioneers, other names were included who held similar views and whom the reviewers or editors found influential.

The results are shown in Table 2: 15 works were reviewed by 40 people. The results are shown as 'positive' (pos) or 'critical' (crit). A translation of a work was treated as a

17 Thomas Preston stated that 'the principle of equivalence established by Joule... is known as the first law of thermodynamics' (Preston 1894, p. 596). 
Table 2 The early response

\begin{tabular}{|c|c|c|c|c|c|}
\hline Publ date & Author & Reviewer & Kind of & Resp date & Publication \\
\hline \multirow[t]{9}{*}{1824} & \multirow[t]{9}{*}{ Carnot } & Laboulaye & pos & 1847 & Dict \\
\hline & & Helmholtz & pos & 1847 & Erhaltung der Kraft \\
\hline & & Matteucci & pos & 1847 & ASP4 \\
\hline & & Thomson W & pos & 1848 & PM33 \\
\hline & & Rankine & pos & 1851 & Edinb Proc 2 \\
\hline & & Clausius & pos & 1850 & AP79 \\
\hline & & Thomson W. & pos & 1850 & PM37 \\
\hline & & Joule & pos & 1845 & PM26 \\
\hline & & Helmholtz & pos & 1845 & Fortschr \\
\hline \multirow[t]{7}{*}{1834} & \multirow[t]{7}{*}{ Clapeyron } & Anonymous & translation & 1837 & Sci Mem 1 \\
\hline & & Anonymous & translation & 1843 & AP59 \\
\hline & & Holtzmann & pos & 1845 & Sci Mem 4 \\
\hline & & Joule & pos, crit & 1845 & PM26 \\
\hline & & Helmholtz & pos, crit & 1847 & Erhaltung der Kraft \\
\hline & & Joule & pos & 1845 & PM26 \\
\hline & & Helmholtz & pos & 1845 & Fortschr \\
\hline 1840 & Faraday & Joule & pos & 1845 & PM26 \\
\hline \multirow[t]{2}{*}{1843} & \multirow[t]{2}{*}{ Joule PM23 } & Helmholtz & pos & 1849 & Fortschr. \\
\hline & & Thomson & pos & 1849 & Edinb Trans 16 \\
\hline 1843 & Grove & Helmholtz & crit & 1848 & Fortschr. \\
\hline \multirow[t]{3}{*}{1844} & \multirow[t]{3}{*}{ Liebig } & Laboulaye & pos & 1847 & Dict \\
\hline & & Jacobi & crit & 1852 & $\mathrm{AC} 34$ \\
\hline & & Thomson & pos & 1852 & PM4 \\
\hline \multirow[t]{2}{*}{$1845 \mathrm{a}$} & \multirow[t]{2}{*}{ Joule PM26 } & Knoblauch & pos & 1845 & Fortschr. \\
\hline & & Verdet & transl exc & 1852 & AC35 \\
\hline $1845 b$ & Joule PM27 & Knoblauch & pos & 1845 & Forschr. \\
\hline \multirow[t]{2}{*}{1845} & \multirow[t]{2}{*}{ Holtzmann } & Helmholtz & pos & $1847 \mathrm{a}$ & Erhaltung der Kraft \\
\hline & & Clausius & pos & 1850 & AP79 \\
\hline \multirow[t]{4}{*}{$1847 \mathrm{a}$} & \multirow[t]{4}{*}{ Joule PM31 } & Wilhelmy & pos & 1847 & Fortschr. \\
\hline & & Wartmann & pos & 1848 & ASP8 \\
\hline & & Poggendorff & transl exc & 1848 & AP73 \\
\hline & & Anonymous & pos, crit & 1848 & Jahresber \\
\hline \multirow[t]{4}{*}{$1847 b$} & \multirow[t]{4}{*}{ Joule CR25 } & Anonymous & crit & 1848 & Jahresber \\
\hline & & Séguin & pos & 1847 & CR25 \\
\hline & & Mayer & crit & 1848 & CR27 \\
\hline & & Person & implicit & 1848 & CR27 \\
\hline \multirow[t]{5}{*}{$1847 \mathrm{a}$} & \multirow[t]{5}{*}{ Helmholtz } & Himself & pos & $1847 b$ & Fortschr. \\
\hline & & Thomson & pos & 1854 & Glasg. Proc. 3 \\
\hline & & Clausius & crit & 1852 & AP86 \\
\hline & & Bosscha & pos & 1857 & AP101 \\
\hline & & Tyndall & translation & 1853 & Sci Mem 6 \\
\hline \multirow[t]{2}{*}{1847} & \multirow[t]{2}{*}{ Séguin CR25 } & Joule & pos & 1849 & CR29 \\
\hline & & Anonymous & pos & 1848 & Jahresber \\
\hline
\end{tabular}


Table 2 continued

\begin{tabular}{llllll}
\hline Publ date & Author & Reviewer & Kind of & Resp date & Publication \\
\hline 1848 & Mayer CR27 & Joule & crit & 1849 & CR29 \\
1849 & Joule CR28 & Helmholtz & pos & 1849 & Fortschr. \\
& Mayer CR28 & Helmholtz & pos & 1849 & Fortschr. \\
& Mayer CR29 & Anonymous & pos & 1849 & Jahresber \\
& Joule CR28 & Anonymous & pos, crit & 1849 & Jahresber \\
\hline
\end{tabular}

AP or Annalen Annalen der Physik; AC Annales de chimie et physique; ASP Archives des sciences physiques; CR25 Comptes rendue v. 25; Dict Dictionnaire des arts, Fortschr Fortschritte der Physik; Sci Mem 4 Taylor's Scientific Memoirs v. 4; Jahresber Jahresbericht über die Fortschritte der reinen, pharmaceutischen und technischen Chemie, Physik, Mineralogie und Geologie; PM26 Philosophical Magazine v. 26; Edinb Proc Proceedings of the Philosophical Society of Edinburgh; Glas Proc Proceedings of the Glasgow Philosophical Society; Edinb Trans Transactions of the Philosophical Society of Edinburgh

positive fact. One important translation was included although it was somewhat earlier (1837).

One result of this study shows lack of interest in the pioneers of the third group. Only Faraday received a positive response for what Kuhn attributed to him. Of Liebig's writings, some analogies between heat, chemical and electromagnetic phenomena drew attention (Laboulaye 1847, c. 2536), sometimes of a rather critical nature (Jacobi 1852, p.472). Grove's book was treated as a 'popular exposition' of transformations of phenomena into one another supplemented with obscure general arguments (Helmholtz 1848, p. 66). And Mohr was completely forgotten.

Of course, silence about certain works at certain times might have resulted from accidental or temporary reasons, such as unavailability of these works in major languages, or in other countries, or their appearance in obscure publications. This is what happened with some pioneers from the first group. The first extract from Colding's works was translated from Danish only in 1864 (Colding 1864), which effectively precluded him from influencing the development of PEC (Verdet 1868, p. XCVII). Also, Helmholtz's major work Über die Erhaltung der Kraft (1847), rejected by Annalen der Physik and published in a separate pamphlet, was little known even in Germany and completely unknown outside it. Fortunately for English scientists, John Tyndall (1820-1893) came across Helmholtz' pamphlet in 1852 and translated it for Taylor's Scientific Memoirs which specialized in translations (Helmholtz 1853). The French translation, however, appeared only in 1869 (Helmholtz 1869).

Sometimes it did not help even when articles appeared in major languages and in well known journals, because these journals were not readily available outside their countries. This is what happened to Mayer's first article in Annalen der Chemie und Pharmacie and several Joule's articles in Philosophical Magazine. As the result, French readers first learned something about Mayer's and Joule's works only in 1847-1849 when the two chose Comptes rendue, a publication of Paris Academy of Science, to dispute the issue of priority. Séguin also joined the debate. ${ }^{18}$ Although his book was in French, it was of the type read by engineers but not scientists, thus his contribution remained unknown even in his native country.

The debate did not provide in-depth information about the new ideas, and French readers had to wait until 1852 when Annales de chimie et physique introduced a new

${ }^{18}$ See Joule (1847b), Joule (1849), Mayer (1848), Mayer (1849), and Séguin (1847). 
section 'Memoirs on chemistry and physics published abroad', to which Émile Verdet supplied excerpts from foreign papers, including those of Mayer and Joule (Verdet 1852a, b, c). Yet, with all its shortcomings the debate provided Mayer with the first real public exposure, and not only to French readers but also to German ones, for it was a subject of reviews in two German review journals (Helmholtz 1849; Anonymous 1849).

Speaking of response to new ideas, we should note an essential difference between the first and the third groups. In five to 10 years the 'neglected' works of the pioneers from the first group, such as Mayer and Helmholtz, became known and appreciated. Colding was an exception, merely because there was no enthusiast around him who understood his ideas and was able and willing to translate his papers into one of the major European languages. However, it was not so for the third group. The relevant works of these scientists were accessible to the public, but their ideas drew an attention only in the 1860 s, when the second stage of the priority dispute between Mayer and Joule provoked an interest in the history of PEC. Regardless of subsequent developments, we may safely assume that lack of prominence of the 'general principle' in our survey means it had no influence on the initial development of PEC. This means, the PEC process did not start with a formulation of a general principle of energy conservation which stimulated the development of particular concepts, such as mechanical equivalent of heat. It will be shown that the opposite happened: it was the development of mechanical equivalent of heat which led to the general principle of energy conservation (GPEC).

A discussion of the third group may be a proper place for a brief digression about metaphysical concepts. This author does not deny metaphysical concepts any role in the GPEC field. It is known that at some point, every GPEC researcher used expressions of the type 'cause equals effect' or 'force cannot be created or destroyed'. Yet, we should distinguish when and why these expressions appeared. Usually it is clear from the context that such expressions served to justify the work already done. It is known that scientists tended to present their ideas to public not in the way they had conceived them, but in the way they believed to be more convincing. And some thought that presence of metaphysical ideas might help with this. As to the process of research, however, while metaphysical ideas might have had a stimulating effect by keeping the researcher at his task, this author could not find a single case where such ideas helped in research by suggesting a new physical concept or a new experiment.

Having found that MEH was at the root of the PEC process, we need to investigate its inner development, in particular, the question of constancy of MEH. Did the researchers believe that MEH was constant? Did they believe MEH constancy should be proven?

\section{Is MEH Constant?}

\subsection{Mayer and Joule}

Mayer said nothing on this account. Readers could have speculated that the only reason for Mayer to give a number without any qualifiers (for example, etc.) would be his belief that the number is constant. On the contrary, Joule set the goal of demonstrating MEH's constancy from his first experiment:

Having proved that heat is generated by the electro-magnetic machine, and that by means of the inductive power of magnetism we can destroy or increase at pleasure the heat due to chemical changes, it became an object of great interest to inquire whether a constant ratio existed between it and the mechanical power gained or lost. (Joule 1843, p. 435) 
He believed that unless MEH was proven constant, the mutual convertibility of heat and work would have remained a hypothesis and not a law. He pursued this task for many years, performing a variety of experiments and improving reliability and precision of his results (see Table 3).

That is why in his debate with Mayer he limited Mayer's role to a prediction of the value of $\mathrm{MEH}$, leaving to himself its proof:

Mayer predicted the numerical relations... between heat and the force, but ... I was the first who have demonstrated the existence of the mechanical equivalent of heat and has determined its numerical value by indisputable experiments (Joule 1849, p.135, italics added).

In other words, Joule did not believe in demonstrability of physical results determined purely theoretically. One of the reasons of his doubts was that certain assumptions Mayer made in his calculations, such, as independence of specific heat of air of its pressure, were in dispute by 1842. Another assumption was that no part of the heat assigned for expansion at constant pressure went for changing the internal conditions of the gas.

Mayer countered Joule's objection about the specific heat of a gas by referring to an old experiment of Gay-Lussac, which, in his opinion, proved that specific heat did not change with a change of pressure. In fact, Mayer's opinion about Gay-Lussac's experiment was not shared by many. However, it will be further argued that the admissibility of Mayer's method of calculations must be viewed from a broader perspective than particular properties of gases.

As shown further, despite Joule's insistence on the crucial role of experiment in determining $\mathrm{MEH}$, subsequent attempts to use theoretical methods similar to Mayer's never stopped. However, before discussing calculations of Mayer's followers, let us check whether his predecessors thought about MEH being constant, because that was what Helmholtz once suggested.

\subsection{Helmholtz}

In 1845, at the inception of the review journal Fortschritte der Physik, published by Berlin Physical Society, Helmholtz became one of the reviewers. In his review of works on physiological heat for that year he said:

The principle of the constancy of the force-equivalents taking place when one natural power is excited by any other, although fully justified logically and already being used as a foundation of mathematical theories (see, for instance, Carnot and Clapeyron about determining the work produced by a certain quantity of heat...), is neither theoretically fully expressed and accepted, nor empirically realized. (Helmholtz 1845 , pp. 349-50, italics added)

This statement is remarkable in two respects. First, it asserts the constancy of the coefficient at which a certain magnitude changes when one phenomenon is transformed into any other. Second, Helmholtz attributes to Carnot and Clapeyron calculations of the work produced by a certain quantity of heat, which is MEH. Let us see if this was true.

\subsection{Was MEH a Constant in Early Thermodynamics?}

It is important to note that none of the pioneers of thermodynamics ever claimed MEH to be a true constant. Indeed, they showed that its magnitude depended on the ratio (or difference) of specific heats at constant pressure and constant volume $\mathrm{Cp}$ and $\mathrm{Cv}$, and there had been a disagreement among physicists and chemists about experimental results on specific heat. Some argued that the results demonstrated that specific heat depended on 
Table 3 Mechanical equivalent of heat

\begin{tabular}{|c|c|c|c|}
\hline Date & Name & $\mathrm{MEH} \mathrm{kGm/kcal}$ & Method \\
\hline 1842 & Mayer & 365 & Theory, air \\
\hline 1847 & Colding & 350 & Friction: metal/metal \\
\hline 1843 & Joule & 460 & Magnetoelectricity/work \\
\hline 1843 & Joule & 425 & Friction of water in tubes \\
\hline 1845 & Holtzmann & 374 & Theory, air \\
\hline $1845 \mathrm{a}$ & Joule & 437 & Condensation/rarefaction \\
\hline $1845 b$ & Joule & 456 & Friction: paddle-wheel/water \\
\hline $1847 \mathrm{a}, \mathrm{b}$ & Joule & 428.8 & Friction: paddle-wheel/water \\
\hline $1847 \mathrm{a}, \mathrm{b}$ & Joule & 429.1 & Friction: paddle-wheel/spermaceti oil \\
\hline $1847 b$ & Joule & 432.1 & Friction: paddle-wheel/mercury \\
\hline 1847 & Séguin & 449 & Steam engine (this number was questioned) \\
\hline 1850 & Clausius & 370 & Theory, air \\
\hline 1850 & Joule & 423.6 & Friction: iron/iron \\
\hline 1850 & Joule & 424.5 & Friction: wheel/water or mercury \\
\hline 1852 & Kupffer & 453 & Stretching a wire \\
\hline 1854 & Hirn & 370 & Friction: metal/metal \\
\hline 1854 & Person & 424 & Theory, speed of sound \\
\hline 1857 & Quintus Icilius & 399.7 & Heat of current in Weber's absolute units \\
\hline 1858 & Hirn & 371.6 & Friction: metal/metal \\
\hline 1858 & Hirn & 425 & Drilling \\
\hline 1858 & Favre & 413.2 & Friction: metal/metal \\
\hline 1862 & Della Casa & 417.8 & Drilling \\
\hline 1862 & Hirn & 432 & Friction of water \\
\hline 1862 & Hirn & 424.5 & Crashing lead \\
\hline 1863 & Dronke & 425.3 & Theory, water vapors \\
\hline 1864 & Tresca and Laboulaye & 433 & Compressed air \\
\hline 1865 & Edlund & 434 & Stretching a wire \\
\hline 1865 & Schröder v. der Kolk & 422.1 & Theory, speed of sound \\
\hline 1865 & Dahlander & 418 & Theory, water vapors \\
\hline 1878 & Joule & 423.8 & Friction: wheel/water \\
\hline
\end{tabular}

volume or pressure, or temperature of a gas, while others interpreted the same results as showing its independence.

Some of Carnot's false assumptions in this area, such that specific heat increases with the volume of a gas (Carnot 1899, p. 32) were based on errors in previous experiments (Delaroche and Bérard 1813, p. 137). Sometimes the conclusion about experimental results was a matter of interpretation. For instance, while Carnot interpreted a non-uniformity of a thermometer scale at high temperatures in experiments by Dulong and Petit as proving that specific heat changes with temperature (Carnot 1899, p. 34), Holtzmann chose to view these results as confirming independence of specific heat of temperature (Holtzmann 1845, p. 195).

The uncertainty with experimental results was not the only reason of variability of $\mathrm{MEH}$. The very nature of Carnot's cycle suggested that MEH was constant only at certain 
conditions. For instance, Clapeyron was explicit that his magnitude $1 / \mathrm{C}$, which was the same as $\mathrm{MEH}$, depended on temperature. In particular, he insisted that the amount of work produced by a unit of heat depended on both temperature levels between which heat 'descended': the result for the transition between $1{ }^{\circ} \mathrm{C}$ and $0{ }^{\circ} \mathrm{C}$ was not the same as between $100{ }^{\circ} \mathrm{C}$ and $99{ }^{\circ} \mathrm{C}$. That was a practical application of the idea first expressed by Carnot that the amount of work obtained in a cycle was greater when the upper level of the heat 'descent' was lower, given the same temperature drop (Clapeyron 1837, pp. 369-70). Later, heavily relying on Regnault's data for vapors (Regnault 1847), Thomson calculated his coefficient $\mu$ presenting mechanical action of a unit of heat as a function of temperature (Thomson 1849, p. 556).

Besides, the quantity of heat absorbed by a gas at the same pressure for a given temperature difference depended on its specific heat. However, the measurements of Delaroche and Bérard, to which everyone referred to, showed that the specific heat for the same volume was about the same for air, nitrogen, and oxygen, it was by $25 \%$ greater for carbonic acid and $55 \%$ greater for ethylene (Delaroche and Bérard 1813, p. 116). Thus, even a selection of a gas for calculations of MEH could have affected the result. For all these reasons, it was not possible to prove at that time that an $\mathrm{MEH}$ obtained theoretically had to be a constant even for gases, not speaking of it being a universal constant.

Having been unaware of thermodynamics and all these difficulties, Mayer rediscovered on his own the thermodynamic method of calculating work produced by heat and made the simplest possible assumptions about properties of gases, in particular, that specific heat of a gas did not depend on temperature, pressure, and volume, or that the ratio of the specific heats $\mathrm{C}_{\mathrm{p}} / \mathrm{C}_{\mathrm{v}}$ was constant (Mayer 1867/1855, pp. 29-30). However, these were not the generally accepted views by 1842 .

A decade later Mayer's case would have been much stronger, for preliminary results of Regnault's experiments provided more support to such assumptions (Regnault 1853). However, by 1862 when Regnault's results were published in full, the priority debate shifted to other issues (Regnault 1862, pp. 298-310). Yet, even then Mayer's result could not have been treated as proving that $\mathrm{MEH}$ is unique, because specific heat varied even for some gases.

It was Mayer's luck, that the number he calculated for air, turned out in the correct range of MEH. However, this became clear only with the publication of Joule's results. More exactly, as shown above, scientists were able to compare them only since 1848 . Actually, there was no rush with such comparisons. It was Clausius who made the first one in 1850. At first, he followed the Mayer-Holtzmann procedure and obtained again $\mathrm{MEH}=370$. However, he agreed with Holtzmann that this result was not precise, ranging between 343 and 429. Then Clausius applied a similar procedure to water vapors and concluded that this result, $\mathrm{MEH}=421$, was more reliable. Comparing it to three Joule's measurements done by different methods-460, 437, and 425-he concluded that their closeness 'leaves really no further doubt of the correctness of the fundamental principle of equivalence of heat and work, and... confirms... the correctness of Carnot's principle, in the form which it takes combined with the first principle'. (Clausius 1850, p. 524; 1851, p. 119)

'(C)orrectness of the fundamental principle of equivalence of heat and work' actually meant the invariability of MEH. That was the first time a person other than Joule proclaimed such a conclusion. Yet, since Clausius added only one new MEH number to Joule's collection and had not yet possessed a reputation in science, this pronouncement did not immediately increase the number of 'converted' to the new theory. Thus, a number of scientists decided to check the supposed invariability of MEH on their own. 


\section{New Determinations of MEH}

Up to 1852, Joule was the lone supplier of experimental MEH, and calculations of Carl Holtzmann (1845) and of Charles Laboulaye (1847) were the only theoretical results obtained in the 1840s independently of Mayer. Laboulaye used a method somewhat similar to that of Carnot and obtained $\mathrm{MEH}=113$.

In 1852, Adolph Theodor Kupffer (1799-1865) carried out the first new experiment, which took place in St. Petersburg (Kupffer 1852). He stretched a wire, first by a weight and then by heat, and, by comparing the quantity of heat and the mechanical work spent in both cases, obtained $\mathrm{MEH}=453$. He considered this result to be close to Joule's measurements.

Unlike Kupffer, Gustave Adolphe Hirn began his experiments in 1854 unaware of previous determinations of $\mathrm{MEH}$ or of the concept of convertibility. Being an engineer, Hirn received an assignment from the Industrial Society of Mulhouse in Alsace to find the best lubricant for moving parts of industrial machines. In the course of his experiments he made a conclusion that 'the absolute quantity of heat developed by a mediated friction is directly and uniquely proportional to the mechanical work absorbed by this friction' (Hirn 1854, p. 202). He obtained $\mathrm{MEH}=370$. After submitting his report to the Society, Hirn learned from a newspaper article by Leon Foucault that he had been anticipated in his discovery (Foucault 1854). The article described the work of Carnot, Mayer, Joule, and Regnault. Entitled 'Mechanical equivalent of heat', the article appeared in the section 'News from the Academy of Sciences'. That was the first historical review of the developments in the field of PEC published in France.

Some physicists claimed that Joule's results were too high, and the correct range had to be around Mayer's number (Anonymous 1847, pp. 56-57). In 1854, having compared four results ( 360 by Mayer, 427 by Joule, 113 by Laboulaye, and 175 by Estocquois ${ }^{19}$ ) Person suggested that the exact number will not be known until the precise value of specific heat at a constant volume $\mathrm{C}_{\mathrm{v}}$ becomes available (Person 1854). The value of $\mathrm{MEH}$ was calculated through the difference $C_{p}-C_{v}$ (see "Appendix 3"), of which $C_{p}$ was measured in experiment, while $\mathrm{C}_{\mathrm{v}}$ was usually calculated by means of the ratio $k=C_{p} / \mathrm{C}_{v}$. The constant $k$ entered Laplace's formula for the speed of sound and could have been determined using experimental data on the speed of sound (Laplace 1822, 1846/1823). In such a way, Person arrived at $\mathrm{MEH}=424$.

Joule interpreted the thrust of Person's article as directed against experimental values of $\mathrm{MEH}$ and suggested that it can

shed doubts in the rigor of the methods that were employed to obtain them $[\mathrm{MEH}]$ and even in the doctrine itself attached to them. However, no physical theory was based on more solid grounds and allowed a greater precision in determining its numerical coefficients. (Joule 1855, p. 310)

However, this response did not stop new challenges to Joule's results. Charles Pierre Lefebvre Laboulaye (1813-1886) revised his 1847 theoretical determination of $\mathrm{MEH}=113$, updating the constants employed at the time and bringing $\mathrm{MEH}$ up to 140 (Laboulaye 1858). He argued that his result was much closer to the truth than Joule's and supposed that Joule's error was due to a loss of some mechanical energy to supports. Since this part of energy did not reach the calorimeter, less heat was produced for the given work which increased the MEH number. Laboulaye offered a new experiment in which a heavy weight fell crashing a lead crown into which was inserted a calorimeter with a certain amount of water. The heat resulting from the crash passed from the crown into the

19 This result was published later, see Estocquois (1858). 
calorimeter, where a thermometer registered a temperature rise. The result was $\mathrm{MEH}=187$, which Laboulaye believed to be closer to truth than Joule's numbers.

Estocquois tried the theoretical method and came up with $\mathrm{MEH}=166$ (Estocquois 1858).

Hirn explored several experimental methods and collected all his measurements in a paper presented to Berlin Physical Society for a contest for an experimental determination of the mechanical equivalent of heat. To explain a considerable scattering of his results (from 371.6 for friction to 425 for drilling) he conjectured that perhaps MEH was a relative rather than an absolute coefficient, and different methods should have produced different results (Hirn 1858). Yet, he tried to reconcile this position with the constancy of MEH:

The variability of experimental mechanical equivalent of heat does not at all involve a loss of movement or living force inside a body. Even less so it involves an idea of an incomplete transformation of heat into moving power or of moving power into heat. (Hirn 1858, p. 242)

This sounded self-contradictory, and Clausius, speaking in the name of the contest commission, told Hirn so. Having noted some deficiencies in Hirn's paper, Clausius highly praised his experimental skills, especially in proving that steam gives less heat to the condenser than it receives from the boiler, by experimenting on a large industrial machine. This determination of MEH was the first where the conversion was not of work into heat, but of heat into work. Clausius advised Hirn to repeat his experiments and to consider them from the position that MEH was an absolute and not a relative constant (Hirn 1858, pp. VVIII).

By that time, two opposite opinions about the proper range of $\mathrm{MEH}$ took shape. One was that small numbers (for instance, below 200) might have meant that only a part of the spent work was consumed, that is, converted into heat. For instance, it was natural to expect that in the case of the crashed lead crown some mechanical energy went to change the molecular structure of the crown, which became visible as a change in its form.

The other opinion was that in converting mechanical work into heat a higher MEH implied that either some heat produced by work was lost and did not enter into calorimetric calculations, or some mechanical power was lost before conversion. That was Rankine's overall view of Joule's results, which he illustrated by the following comment on Joule's magneto-electric experiment:

To make the determination of the mechanical equivalent of heat by electro-magnetic experiments correct, it is necessary that the whole of the mechanical power should be converted into magnetic power, the whole of the magnetic power into what are called electric currents, and the whole of the power of the electric currents into heat, not one of which conditions is likely to be exactly fulfilled.

(Rankine 1853a, p. 157)

On the basis of this pessimistic attitude, Rankine recommended the theoretical method, in particular, obtaining the ratio of specific heats $\mathrm{C}_{\mathrm{p}} / \mathrm{C}_{\mathrm{v}}$ from Laplace's formula for sound.

However, Laplace's formula required precise measurements of the speed of sound, which was not an easy task whether done in the laboratory or in the field. Antoine Masson employed the former method by measuring the speed of sound in different gases filling the same organ pipe (Masson 1858). By making the pipe to resonate and comparing the frequency of the tone produced with the wavelength of a standing wave created in the pipe he was able to calculate the speed of sound in each gas. From these data Masson calculated for air $\mathrm{k}=\mathrm{C}_{\mathrm{p}} / \mathrm{C}_{\mathrm{v}}=1.4196$, from which it followed that $\mathrm{MEH}=419$ (ibid., pp. 269-272).

Schröder van der Kolk decided to try his luck with the field measurements of sound (Schröder van der Kolk 1865a, b). Since such measurements were difficult and expensive to carry out, he chose the experiment already done and considered the best-the 1823 
experiment of Moll and van Beck-and recalculated the result by modifying the theory. He supposed that since the sound of a canon, usually employed in such experiments, is of a very high intensity, there was a possibility that this affected the speed of sound. He introduced intensity of sound as a variable into the theory of sound propagation and found that sound diminished its speed when the wave spread in space and its intensity decreased. However, the average velocity differed only imperceptibly from the one calculated in an ordinary way. Yet, the recalculation did change somewhat the result, because it introduced corrections, including the effect of wind, and more accurate constants. The result was $\mathrm{V}=332.77 \mathrm{~m} / \mathrm{sec}$, which led to $\mathrm{k}=\mathrm{C}_{\mathrm{p}} / \mathrm{C}_{\mathrm{v}}=1.4128$ (ibid., pp. 469-470). From these he calculated $\mathrm{MEH}=422.1$ (Schröder van der Kolk 1866, pp. 348-49).

In a way, the dispute over which method of determining MEH, experimental or theoretical, was more reliable ended in a draw, because the two provided similar results and because some physicists used both. Actually the dispute ended with a realization that the important part was not the method itself-both required precise experimentation-but the choice of the phenomenon to apply it to and the selection of conditions for running an experiment. For example, Hirn concluded from his experiments that a peculiarly large deviation of an experimental result from the results of others might have been caused by 'a bad choice of an experimental procedure' (Hirn 1865, p. 50). In time, physicists recognized that good procedures were such which reduced losses of heat or work. Joule considered the friction of fluids to be one (Joule 1850).

By the middle of the 1860s the principle of convertibility together with a constant MEH was 'accepted almost everywhere by all the physicists' (Hirn 1865, p. 9). This changed the purpose of new determinations of MEH: it was no longer necessary to prove the constancy of $\mathrm{MEH}$, but only to determine its most correct value. This involved a more careful selection of phenomena and experimental procedures and taking care of various corrections. At this point it became clear that theoretical methods relying on expansion of airsimilar to that of Mayer-are viable, because air at normal pressure does not consume heat to change its molecular structure. While completely useless in 1842 for demonstrating the constancy of $\mathrm{MEH}$, this method became valuable later when this constancy had been already proven otherwise and it became important to find the best phenomenon and procedure for a reliable calculation of MEH. As shown above, by using updated constants for speed of sound, specific heat and the coefficient of thermal expansion Mayer's procedure in the hands of others improved the original number bringing it close to the best experimental results.

\section{Mutual Conversion or 'Coexistence' of Heat and Work?}

Although calculations of work created by a unit of heat became routine in the early thermodynamics, the result did not acquire any special meaning. Certainly neither Carnot and Clapeyron nor Holtzmann and Thomson thought before 1850 that heat could be converted into work. Apparently, before 1850 they assumed a certain association between heat and work, such that the two existed independently of one another but could influence each other.

For instance, Carnot's supposition that work was created by a mere transfer of heat by expanding gas, in fact, implied such a coexistence. And even Clausius did not deny it outright: 
It is quite possible that in the production of work both may take place at the same time; a certain portion of heat may be consumed, and a further portion transmitted from a warm body to a cold one; and both portions may stand in a certain definite relation to the quantity of work produced. (Clausius 1864 , p. 17 , italics added)

The last part of this quote is somewhat obscure, but it did not produce any objections.

Sometimes coexistence was hidden behind such words as 'proportionality' or 'equivalence', which indicated a numerical relation between heat and work and nothing more. These terms appealed to scientists who were not yet convinced that heat and work are mutually convertible. With such a term they could accept Joule's experimental results as showing mere a proportionality and to abstain from deciding about conversion.

Holtzmann was one of them. He not only readily acknowledged the existence of proportionality, but even employed it for practical purposes: to measure heat by mechanical work. He saw a support of proportionality as an opposition to convertibility, and he criticized Clausius for adopting the principle of convertibility (Holtzmann 1851).

Another advocate of proportionality and opponent of convertibility was Moritz Hermann von Jacobi (1801-1874). In his view,

This equality or rather this admirable proportionality between heat and work developed by current does not give us, however, the right to speak, as Joule has done, of an transformation of the heat into mechanical work. (Jacobi 1852, pp. 474-75, italics added)

A variety of terms used at the time to indicate that a certain amount of work corresponded to a unit of heat, such as 'proportionality', 'equivalence', 'transformation', and 'conversion' sometimes confuse scholars who do not define them rigorously. For instance, as quoted above, Kuhn stated

Sadi Carnot, before 1832, Marc Séguin in 1839, Karl Holtzmann in 1845, and G. A. Hirn in 1854, all recorded their independent convictions that heat and work are quantitatively interchangeable, and all computed a value for the conversion coefficient or an equivalent. (Kuhn 1959, p. 321, italics added)

The problem with this statement is that at the times indicated in the quote Carnot and Séguin adopted conversion but Holtzmann and Hirn only accepted proportionality. Thus, whatever 'quantitatively interchangeable' means-conversion or proportionality-this term is not applicable to all four. Likewise, 'conversion coefficient' is not proper for Holtzmann and Hirn. Apparently, Kuhn found the distinction between conversion and proportionality immaterial.

In another example D. Cardwell quoted a long passage from an 1808 article of Peter Ewart of Manchester as supposedly asserting

the fundamental axiom of the equivalence of heat and work. It is not, of course, a statement of the mutual convertibility of heat and mechanical energy... but it was an essential step in that direction. (Cardwell 1971, p. 163)

However, an examination of the passage shows nothing about equivalence as defined in this paper. Ewart's article is about finding the best definition of force and the role of time in these definitions (Ewart 1813, pp. 167-69). For an illustration, he compares fall of water with burning coal. The argument is as follows. If a mechanical action is defined by vis viva, whether the given mass of water falls from a given height fast (through a wide channel) or slowly (by a narrow channel) it will produce the same work. Likewise, whether you burn the same amount of coal fast or slowly, the total work obtained from the steam will be the same.

In fact, the only thing this passage says is that the same amount of potential or internal energy can be used up for work in a shorter or a longer period of time. Ewart confuses the total heat released, which remains the same, indeed, with the total work obtained from heat, which is contingent upon conditions at which heat produces work in an engine. As 
one critic indicated, the analogy had no practical significance, because if the coal burned too fast or too slowly the amount of work obtained from a steam engine could be made very small.

The idea of proportionality made the issue of constancy of MEH even sharper. Indeed, had the amount of work produced by a unit of heat under similar circumstances varied in a random fashion, there would have been no 'numerical relation' at all, that is, no proportionality. Thus, the key to the issue of constancy, even in a limited sense, is in preserving the circumstances: as long as the relevant circumstances (for instance, pressure, temperature, and volume of a gas) are fully recreated, one unit of heat should always produce the same quantity of work.

Apparently, it was acceptance of this condition, perhaps an implicit one, that gave meaning to thermodynamics before PEC. As long as physicists accepted a certain numerical relation between work and heat, whatever its nature, mathematics could have functioned even without PEC. Sometimes this led to errors, for instance, the concept of proportionality was unable to produce a correct MEH number, because the quantity of heat selected for calculations did not physically correspond to the work it supposedly produced ("Appendix 1 "). However, in a number of cases the pre-PEC thermodynamics produced valuable results which earned praise even from such PEC promoters as Helmholtz and Clausius.

In fact, accepting the notion of MEH did not necessarily mean adopting the convertibility. With or without PEC, the same output of work per unit of heat was supposed to be produced whenever all the conditions of the experiment were exactly replicated, and the heat producing work was correctly identified. This may mean that for some scientists accepting mutual convertibility of heat and work could have been a two-step process: at first, they adopted merely the idea of proportionality (or of a constant $\mathrm{MEH}$ ), and later replaced proportionality with conversion. One fact in support of this suggestion is a proliferation of such terms as 'proportionality' and 'equivalence'. Another is that while there were objections to the concept of convertibility of heat and work, the idea of proportionality never experienced any criticism. No one found it to be strange that when heat produced work or work created heat, there was a constant quantitative relation between them. As an example, reviews of Joule's early measurements of MEH listed them in a matter-of-fact manner, as if the subject under inquiry were a very familiar concept, such as specific heat (Wilhelmy 1847, p. 230).

\section{Maturity}

In the 1860 s several signs appeared that the mechanical theory of heat had already been sufficiently entrenched into science as a new research field.

First, challenges came to an end. Hirn no longer questioned absolute constancy of MEH. In 1862 he published a book with new experiments which all confirmed that MEH was constant (Hirn 1865). Those who had argued that the true value of MEH must be very different from Joule's results either did new experiments and recanted their opinion or left the field (Tresca and Laboulaye 1864).

Second, articles began to appear about the history of the new theory. Some of them dealt only with the priority claims, ${ }^{20}$ while others painted a broader picture including new works done since late 1840 s. $^{21}$

\footnotetext{
${ }^{20}$ See, for instance, Colding (1864), Joule (1862), Tait (1864), Tyndall (1862), Verdet (1863).

21 Such as Bertin (1867), Bohn (1864), and Verdet (1868).
} 
Third, full translations of the pioneers' works, and monographs and popular books by others began to appear. ${ }^{22}$

Finally, the concepts of mechanical theory of heat and mechanical equivalent of heat began to appear in some textbooks. Their authors gave prominence to new ideas by placing the terms 'Mechanical theory of heat' or 'Mechanical equivalent of heat' in the tables of content. To achieve this they employed these terms in the titles. Naturally, the titles of large chapters or lessons ${ }^{23}$ were more visible there than those of small sections. ${ }^{24}$ By comparing different editions of the same book, one can see that with time the new theory acquired more space in textbooks or improved its status by moving from a section to a chapter level. For instance, in 1864 the textbook by Johann Heinrich Jacob Müller (1809-1875) had a 3-page section 'Mechanical equivalent of heat'in the chapter 'Sources of heat', but 4 years later this chapter changed its title to 'Sources of heat and the mechanical theory of heat', which included in addition to the section on $\mathrm{MEH}$ various applications of the theory comprising in total 50 pages (Müller 1864, pp.794-797; Müller 1868, pp. 886-936).

French textbooks introduced the new theory even earlier. A popular elementary physics text by A. Ganot had a section on MEH as early as 1856. Although small, it provided a detailed history of the new theory (Ganot 1856, pp. 310-11). Another elementary physics textbook by P. A. Daguin had nothing on the new theory in 1855, but 6 years later it had a section on 'Mechanical equivalent of heat' of 14 pages (Daguin 1855, 1861, pp. 504-518). Likewise, Jules Jamin (1818-1886) had upgraded the status of the new theory from a 8-page section on MEH in 1859 to a chapter of 37 pages on 'Mechanical theory of heat' in 1868 (Jamin 1859, pp. 432-440, Jamin 1868, pp. 430-467). Some authors, however, even of college-level textbooks, avoided the new theory altogether (Pouillet 1856, Desains 1865).

\section{Conclusions}

It was found that up to 1870 the ideas expressed by Mayer and Joule which included the principle of convertibility (equivalence) of heat and work and a constant numerical coefficient of such a conversion (mechanical coefficient of heat or $\mathrm{MEH}$ ) practically constituted the whole extent of the theory subsequently known as the principle of energy conservation and transformation and which is called here the 'new theory'.

While historically this theory had been applied sometimes to other phenomena as well, for the purposes of historical research these cases were moved to Part II in another paper which will serve as a continuation of this one. It turned out that such a separation is possible, because everything necessary for establishing the new theory, which included proving the constancy of MEH and determining a reliable value for it, was sufficiently accomplished within the framework of mechanical and thermal phenomena.

The research related to the new theory consisted of two components. One was new: determining $\mathrm{MEH}$ by experimental or theoretical methods. The other was old, it was thermodynamics of Carnot and Clapeyron. This thermodynamics was revived in the 1840s primarily by Holtzmann and Thomson. The stimulus for this development came from the need to improve steam engines.

At first, thermodynamics was not connected to the new theory. Holtzmann and Thomson pursued the old lines of research set by Carnot and Clapeyron trying to make improvements. It

\footnotetext{
${ }^{22}$ For instance, Briot (1869), Grove (1850), Helmholtz (1869), Secchi (1869), Tyndall (1863a), Verdet (1872), and Zeuner (1869).

${ }^{23}$ Among them, Quintus Icilius (1855), Fick (1866), Privat-Deschanel (1869), Gréhant (1869).

${ }^{24}$ See Cook (1860), Eisenlohr (1863), Silliman (1865), Ganot (1868).
} 
was Joule who initially brought the two components together, directly and indirectly. His direct contribution consisted of applying in 1845 the new theory to the theory of steam engine (qualitatively) and correcting Carnot that the quantity of heat given away by steam to a condenser was less than the one received from the boiler, and it was their difference that created mechanical work (Joule 1845a, p. 383). He was unaware that Séguin expressed exactly same idea 6 years earlier. Indirectly, Joule's multiple experiments from 1843 to 1849 convinced Thomson, Clausius, and Rankine that MEH was constant which implied that the principle of convertibility was true, and if obtaining work in an engine required disappearance of a part of heat, the old thermodynamics was in trouble.

Rankine and Clausius were the first to make a correction by replacing Carnot's hypothesis about the equality of the quantity of heat possessed by steam throughout the cycle with the principle of convertibility. Thomson followed them soon, and the three became the leaders of the new (or modified) thermodynamics.

Between 1850 and 1870, the new thermodynamics was frequently called the mechanical (or dynamical) theory of heat.

A survey of papers published between 1840 and 1870 revealed (Table 1) that researchers considered the most influential the following people (in this order): Joule, Carnot, Mayer (1845-1850), Joule, Clausius, Carnot (1851-1861), and Joule, Thomson, Clapeyron, Clausius and Mayer (1862-1872). Thus, they considered thermodynamics and the new theory equally important and interconnected.

Unbeknown to Mayer, his method of calculating MEH had been known before: it was a regular component of research in early thermodynamics. However, the numbers obtained by Carnot and Clapeyron were much lower than those obtained in the post-1842 period. Their error consisted of not using a correct quantity of heat which corresponded to the work produced. The correct one would have been the quantity consumed during Carnot cycle, that is a difference between the quantity absorbed by steam/gas from the boiler and the quantity given away to condenser. The problem was that in Carnot-Clapeyron theory such difference was exactly zero. Thus, a correct calculation of MEH was impossible within that theory. Mayer and Holtzmann succeeded because they used a single isobaric expansion instead of the cycle. In such a process, all the heat absorbed by steam/gas goes only for work of expansion, thus the quantities of heat received and work produced always correspond to one another with respect to calculating MEH. They were lucky, for neither suspected such complications.

Since the early thermodynamics did succeed in solving a number of problems, it is possible, that this success was connected with the idea of limited constancy of MEH: as long as all conditions (for instance, pressure, volume, and temperature of a gas) were the same, MEH was constant. This problem requires an additional investigation.

Judging from the work of Carnot, Clapeyron, and Mayer (1842), the idea of constancy of MEH was conceived theoretically. It took two decades of experiments to remove any doubts about universal constancy of MEH. Subsequent experiments served merely to find the most reliable value for $\mathrm{MEH}$.

During the first seven years when he experimented alone, Joule singlehandedly produced results which appeared to Rankine, Clausius, and Thomson sufficiently convincing respecting constancy of $\mathrm{MEH}$ to begin reforming thermodynamics on the basis of the principle of convertibility.

This paper is the first part of a planned three-part project under a conditional name 'How the principle of energy conservation evolved between 1842 and 1870: an inside view'. The second part will be 'Creating a general principle of energy conservation', and 
the third, 'The role of the vibratory (wave) theory of heat'. Naturally, readers should not expect find in this paper answers to questions reserved to other parts.

\section{Appendix 1}

\section{The Error}

Since considerations of Carnot and Clapeyron in calculating MEH were similar, we will combine them and use Clapeyron's graphical representation of the Carnot cycle for a greater clarity. The purpose of this comment is to try to explain why MEH calculated by Carnot and Clapeyron was so small, 1.4, compared to Mayer's and Holtzmann's numbers about 370. Mach reproduced Carnot's calculation of MEH in full, but made no comment on the result, although the title of his book included the words 'historical-critical' (Mach 1896, p. 223).

Since mathematical analysis of specific heats by Carnot and Clapeyron is complicated and does not throw any light on the nature of their error, I will omit it and focus instead on the physical analysis of the processes in Carnot cycle, comparing their considerations with the correct ones.

Both Carnot and Clapeyron consider work done during a complete cycle, which consists of a positive work of expansion from volume $V_{1}$ to volume $V_{2}$ at the constant temperature $\mathrm{T}_{1}$ (illustrated by the area $12 \mathrm{~V}_{2} \mathrm{~V}_{1}$ ) and a negative work of compression from the volume $\mathrm{V}_{3}$ to volume $\mathrm{V}_{4}$ at the temperature $\mathrm{T}_{2}$ (the area $43 \mathrm{~V}_{3} \mathrm{~V}_{4}$ ). It is clear that the total work is represented by an area of a curved quadrangle 1234, which decreases when the temperature difference diminishes. It is evident that if changes in volume $\delta V$, pressure $\delta \mathrm{P}$ and temperature $\delta t$ are small the quadrangle can be approximated by a rectangle whose one side will be the maximal difference in pressure $\delta P$, and the other, the maximal difference in volume $\delta V$. Thus, the total work performed by the gas will be $\mathrm{W}=\delta \mathrm{P} \delta \mathrm{V}$.

Apparently, this calculation of work was correct. The trouble occurred with the calculations of the heat $\mathrm{Q}$ which produced this work $\mathrm{W}$ and was supposed to enter the equation $\mathrm{MEH}=\mathrm{W} / \mathrm{Q}$. The calculations of Carnot and Clapeyron include two rather unexpected steps. First, they considered the heat obtained by the gas only at the stage of expansion, rather than in the whole cycle. Second, they appear to view expansion as isobaric rather than isothermal 12 and adiabatic 23, as supposed to be in Carnot's cycle.

We will start with the second puzzle. The quantity of heat $\mathrm{Q}$ received by a gas of a mass $m$ to warm it up at constant pressure by the temperature $\delta t$ is $\mathrm{Q}=\mathrm{C}_{\mathrm{p}} \mathrm{m} \delta \mathrm{t}$., where $\mathrm{C}_{\mathrm{p}}$ is its specific heat at constant pressure. The reason for using $\mathrm{C}_{\mathrm{p}}$ is simple: there were no other experimental data for specific heat of gases, only the ones obtained at constant pressure. But this does not mean Carnot and Clapeyron considered the whole expansion as isobaric. If they did, they would have used only about one-third of $\mathrm{C}_{\mathrm{p}}$, because, as Carnot indicated himself, in an isobaric process only a fraction of $C_{p}$, namely, $C_{p}-C_{v}$, where $C_{v}$ is specific heat at a constant volume, affects expansion, the rest going to warm the gas up.

Perhaps, Carnot and Clapeyron considered expansion as follows. The gas being at $0{ }^{\circ} \mathrm{C}$ contacted the hot body at $1{ }^{\circ} \mathrm{C}$ and began to expand until its temperature reached $1{ }^{\circ} \mathrm{C}$. This part is isobaric, it will be brief. If the temperature $\mathrm{T}_{1}$ of the hot body will be supported afterwards at the level slightly higher that $1{ }^{\circ} \mathrm{C}$, the gas will continue receiving heat at the temperature $1{ }^{\circ} \mathrm{C}$. This will be an isothermal process 12 when all the incoming heat goes for expansion. The adiabatic part 23 does not concern us, because there will be no heat exchange then. 
Fig. 1 Clapeyron's diagram of Carnot's cycle

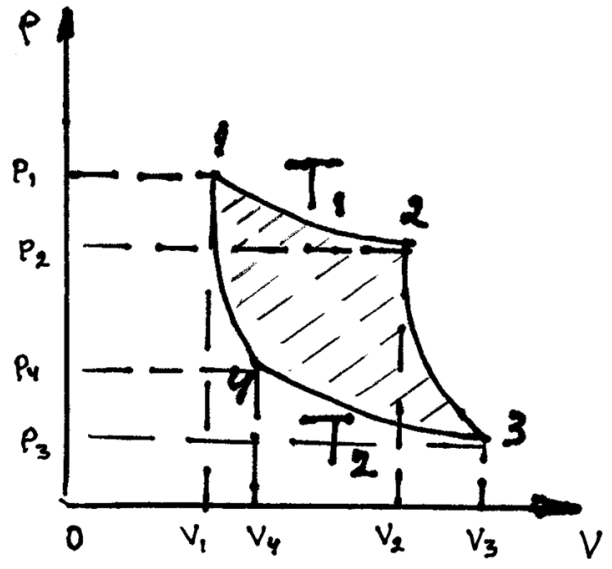

Let us now turn to the first puzzle. In Carnot's theory, during compression at the stage 34 the gas gave away to the cold body the total amount of heat Q it received from the hot body at the expansion stage 12. In this way it preserved its own total amount of heat. In this theory there was no heat converted into work as it is in the corrected theory, where $\mathrm{Q}_{34}$ is less than $\mathrm{Q}_{12}$ and it is their difference $\mathrm{Q}_{12}-\mathrm{Q}_{34}$ which is converted into work. Thus, Carnot and Clapeyron had no other choice for the quantity of heat to calculate MEH than the one they did take.

Let us estimate how much heat would have been converted into work for $1 \mathrm{~kg}$ of air at normal pressure and temperature $0^{\circ} \mathrm{C}$, if temperatures of the hot and cold bodies were, respectively, $1{ }^{\circ} \mathrm{C}$ and $0{ }^{\circ} \mathrm{C}$. In the corrected Carnot theory we would have

$\mathrm{W}=\left(\mathrm{Q}_{12}-\mathrm{Q}_{34}\right) / \mathrm{Q}_{12}=\left(\mathrm{T}_{1}-\mathrm{T}_{2}\right) / \mathrm{T}_{1}$. The gas will expand while receiving heat until its temperature will reach $1^{\circ} \mathrm{C}$. Assuming, as before, the initial part of expansion isobaric, the heat received will be the same as calculated by Carnot, or $\mathrm{Q}_{12}=0.267 \mathrm{kcal} / \mathrm{kg}$. Then $=\left(\mathrm{Q}_{12}-\mathrm{Q}_{34}\right) / \mathrm{Q}_{12}=273-272 / 273=1 / 273$. Thus, the amount of heat converted into work is $\left(\mathrm{Q}_{12}-\mathrm{Q}_{34}\right)=\mathrm{Q}_{12} / 273=0.267 / 273=0.00097 \mathrm{kcal}$. According to Carnot, the work produced under these conditions was $\mathrm{W}=0.372 \mathrm{kGm}$, thus $\mathrm{MEH}=0.372 /$ $0.00097=383.5 \mathrm{kGm} / \mathrm{kcal}$. This is about the same as calculated by Mayer and Holtzmann. It appears that our model of expansion works (Fig. 1).

\section{Clapeyron's Equation for Vapors}

The error in calculating MEH does not negate the whole theory of Carnot and Clapeyron. As a positive achievement of this theory one can note Clapeyron's application of his theory to vapors which resulted in the following equation:

$$
k=\left(1-\frac{\delta}{\rho}\right) \frac{d p}{d t} C
$$

where $\mathrm{MEH}=1 / \mathrm{C}, k$ is specific heat of evaporation, $\delta$ and $\rho$ are densities of vapors and the liquid. In many cases this equation can be reduced to

$$
\frac{1}{C}=\frac{\frac{d p}{d t}}{k}
$$

Clapeyron used (2) to determine $\mathrm{MEH}$ for vapors of several liquids, which ranged from 1.36 to 1.08 , diminishing with the rise of temperature. 


\section{Appendix 2}

Let heat required to warm up a gas at a constant volume $\mathrm{V}$ be $\mathrm{X}$, then heat to raise the gas to the same temperature at a constant pressure $\mathrm{P}$ is $\mathrm{X}+\mathrm{Y}$, where $\mathrm{Y}=\mathrm{Fx}$, where $\mathrm{F}$ is force, and $\mathrm{x}$ is distance. [Y is work but Mayer does not use this term] If we warm up $1 \mathrm{~cm}^{3}$ of air at the constant pressure $\mathrm{P}$ by $\delta \mathrm{t}=1{ }^{\circ} \mathrm{C}$, it will expand by $1 / 274$ part of its volume. If the air makes a column with a base of $1 \mathrm{~cm}^{2}$, it will extend by $1 / 274 \mathrm{~cm}$. This air column will be subjected to atmospheric pressure represented by a mercury column of $76 \mathrm{~cm}$ high. The additional pressure will raise this mercury column by $1 / 274 \mathrm{~cm}$. Since the weight of this mercury column is $1033 \mathrm{G}$, the effort produced is $\mathrm{Y}=\mathrm{Fx}=1,033$ / $274=3.77 \mathrm{Gcm}=0.0377 \mathrm{Gm}$ (here $\mathrm{G}$ is gram of force, $\mathrm{kG}$-kilogram of force: 1 $\mathrm{kG}=9.8 \mathrm{~N})$.

The mass of $1 \mathrm{~cm}^{3}$ of air is $0.0013 \mathrm{~g}$, and specific heat for air at constant pressure $\mathrm{C}_{\mathrm{p}}$ (from direct experiments) is $0.267 \mathrm{cal} / \mathrm{gdeg}$. The specific heat at a constant volume $\mathrm{C}_{\mathrm{v}} \mathrm{can}$ be calculated from the ratio $\mathrm{C}_{\mathrm{p}} / \mathrm{C}_{\mathrm{v}}=1.421$ from Dulong's experiment (Dulong 1829). Thus, $\mathrm{C}_{\mathrm{v}}=0.267 / 1.421=0.188 \mathrm{cal} / \mathrm{g}$ The heat necessary to warm up a mass $m$ of gas by the temperature $\delta \mathrm{t}$ at the constant pressure would be $\mathrm{X}+\mathrm{Y}=\mathrm{C}_{\mathrm{p}} \mathrm{m} \delta \mathrm{t}$, but if done at the constant volume, the required heat would be $\mathrm{X}=\mathrm{C}_{\mathrm{v}} \mathrm{m} \delta$. The excess of the quantity of heat necessary in the former process compared to that in the latter goes into the work of expanding the gas. Thus, the heat spent on expansion is $\mathrm{Y}=\mathrm{C}_{\mathrm{p}} \mathrm{m} \delta \mathrm{t}-\mathrm{C}_{\mathrm{v}} \mathrm{m}$ $\delta \mathrm{t}=(0.267-0.188) \times 0.0013 \times 1=0.000103 \mathrm{cal}$. If the heat of 0.000103 cal produces $0.0377 \mathrm{Gm}$ of work, then $1 \mathrm{kcal}$ will create $366 \mathrm{kGm}$, which means $\mathrm{MEH}=366$ $\mathrm{kGm} / \mathrm{kcal}$.

Note that Mayer considers only an expansion of a gas, not the whole cycle as Carnot and Clapeyron did.

\section{Appendix 3}

Holtzmann starts with Clapeyron's equation $\mathrm{p}=\mathrm{k} \rho(1+\alpha \mathrm{t})$ and his definition of proportionality between work $\mathrm{dW}=\mathrm{pdv}$ and a quantity of heat $d q: \mathrm{pdv} / \mathrm{dq}=\mathrm{a}$ where $a$ is $\mathrm{MEH}$. Then he considers the quantity of heat in a gas as a function of pressure $p$ and density $\rho$. Like Clapeyron, he obtains expressions for $\mathrm{C}_{\mathrm{p}}$ and $\mathrm{C}_{\mathrm{v}}$ as derivatives from the quantity of heat $q$ at constant pressure and constant volume, respectively. However, he makes one step farther by relying on the experimental value of $\mathrm{C}_{\mathrm{p}} / \mathrm{C}_{\mathrm{v}}=1.415$ and assuming $C_{p}$ to be independent of temperature and pressure. He eliminates extra parameters, assumes Carnot's function $\mathrm{F}_{\mathrm{t}}$ to depend on temperature only, and expresses it as $\mathrm{F}_{\mathrm{t}}=\mathrm{A}+\mathrm{bt}$ where $A$ and $b$ are constants. Having obtained in this way the value of $\mathrm{C}_{\mathrm{p}}-$ $\mathrm{C}_{\mathrm{v}}=0.08$ he comes up with $\mathrm{MEH}=374 \mathrm{kGm} / \mathrm{kcal}$.

In fact, although using Clapeyron's mathematical intricacies, he simplified the problem to the level of Mayer's: using a single expansion instead of a cycle, and an isobaric expansion to that. In such a process, all the quantity of heat received by the gas goes for expansion and none for warming up the gas $(\mathrm{t}=\mathrm{const})$. Thus the conditions for coupling corresponding quantities of heat and work necessary for a calculation of MEH are fulfilled automatically, and the result must be correct (within the precision of the constants involved). Thus, Mayer and Holtzmann were simply lucky with this calculation, for they had no idea of all the difficulties described in "Appendix 1". 


\section{References}

Anonymous. (1847-48). Wärmelehre. Jahresbericht über die Fortschritte der reinen, pharmaceutischen und technischen Chemie, Physik, Mineralogie und Geologie [further: Jahresbericht], 47-122 (esp. 56-57).

Anonymous. (1849). Wärmelehre. Jahresbericht, 23-50 (esp. 28-29).

Bertin, (1867). Rapport sur les progrès de la thermodynamique en France. Paris: Imprimerie Impériale.

Birckbeck, G., \& Adcock, H. J. (1827). The steam engine theoretically and practically displayed. London: J. Murray.

Bohn. (1864). Historic notes on the conservation of energy. Philosophical Magazine 28, 311-314, 29, $215-218$.

Boyer, C. (1959). Commentary on the papers of Thomas S. Kuhn and I. Bernard Cohen. In M. Clagett (Ed.), Critical problems in the history of science (pp. 384-390). Madison, WI: University of Wisconsin Press.

Breithaupt, J. (2003). Teach yourself physics. New York: McGraw-Hill.

Briot, Ch. (1869). Théorie mécanique de la chaleur. Paris: Gauthier-Villars.

Brojan, J. (1983). Teaching about energy. Physics Education, 18, 204-205.

Bunge, M. (2000). Energy: Between physics and metaphysics. Science \& Education, 9, 457-461.

Caneva, K. (1993). Robert Mayer and the conservation of energy. Princeton, NJ: Princeton University Press.

Cardwell, D. (1971). From Watt to Clausius: The rise of thermodynamics in the early industrial age. Ithaca, NY: Cornell University Press.

Carnot, H. (1878). A letter to President of the Académie des Sciences of November 30, 1878. Comptes rendus hebdomadaires des séances de l'Académie des Sciences [further, Comptes rendus], 87, 967-969.

Carnot, S. (1978/1824). Réflexions sur la puissance motrice du feu. A critical edition with an Introduction and Commentaries by R. Fox. Paris: J. Vrin. In English: Carnot, S. (1899/1824). Reflections on the Motive Power of Heat. In Magie, W (ed.) The second law of thermodynamics: Memoirs by Carnot, Clausius and Thomson (pp. 1-60). New York \& London: Harpers \& brothers.

Clapeyron, É. (1834). Mémoire sur la puissance motrice de la chaleur. Journal de l'École Royale Polytechnique, XIV((cah. 23)), 153-190.

Clapeyron, É. (1837). Memoir on the motive power of heat (translated from the French). Scientific Memoirs, $1,347-376$.

Clapeyron, É. (1843). Ueber die bewegende Kraft der Wärme (translated from the French). Annalen der Physik und Chemie [further, Annalen], 59, 446-464; 566-58.

Clausius, R. (1850). Ueber die bewegende Kraft der Wärme und die Gesetze, welche sich daraus für die Wärmelehre selbst ableiten lassen. Annalen, 79(3), 368-397, 500-524. In English: Clausius, R. (1851). On the moving force of heat, and the laws regarding the nature of heat itself which are deductible therefrom. Philosophical Magazine, 2, 1-21; 102-119, or, Clausius, R. (1864). The mechanical theory of heat with its applications to the steam engine, etc., v. 1. London: J. v. Voorst, pp. 14-69.

Clausius, R. (1854). Ueber eine veränderte Form des zweiten Hauptsatzes der mechanischen Wärmetheorie. Annalen, 93, 481-506.

Coelho, R. (2009). On the concept of energy: How understanding its history can improve physics teaching. Science \& Education, 18, 961-983.

Coelho, R. (2013). On the concept of energy: Eclecticism and rationality. Science \& Education. doi:10. 1007/s11191-013-9634-1.

Colding, A. (1849). Om de almindelige Naturkræfter og deres giensige Afhængighed. Forhandlinger ved de Skandinaviske Naturforskeres. In Proceedings of the Fifth Meeting of the Scandinavian Scientists, 12-17 July, Kopenhagen, 1847 (pp. 208-239).

Colding, A. (1864). On the history of the principle of the conservation of energy. Philosophical Magazine, $27,56-64$.

Colding, A. (1972/1843). Investigation Concerning the Universal Forces of Nature and Their Mutual Dependence and Especially Concerning the Heat Evolved from the Friction of Certain Solid Bodies (translated from an 1850 Danish publication). In Dahl, F. (Ed.) Ludvig Colding and the Conservation of Energy Principle (pp. 19-45). New York: Johnson Reprint Corp.

Cook, J. (1860). Elements of chemical physics (pp. 484-489). Boston: Little, Brown, \& Co.

Cotté, M. (2002). Les apports de Marc Séguin à la naissance de la thermodynamique. In Kragh, H., Vanpaemel, G, \& Marage, P. (Eds.). History of modern physics. Proceedings of the XXth International Congress of History of Science (Liège, 20-26 July 1997), v. XIV., pp. 125-132. Brepols.

Daguin, P. A. (1855). Traité élémentaire de physique théorique et expérimentale, v.1, Toulouse: E Privat. Paris: Dezobry \& Magdeleine.

Daguin, P. A. (1861). Traité élémentaire de physique théorique et expérimentale (2nd edition), v. 2. Toulouse: E. Privat (pp. 504-518). Paris: Dezobry \& Macdeleine. 
Dahlander, G. R. (1865). Sur un détermination de l'équivalent mécanique de la chaleur. Annales de Chimie et physique [further, Annales], 4(4), 474-477.

Delaroche, F., \& Bérard, J. (1813). Mémoire sur la détermination de la chaleur spécifique des différent gaz. Annales, 85(72-110), 113-182.

Desains, P. (1865). Leçons de physique (Vol. 2). Paris: Tandu.

Doménech, J., et al. (2007). Teaching of energy issues: A debate proposal for a global reorientation. Science \& Education, 16, 43-64.

Dronke, A. (1863). Zur mechanischen Wärmetheorie. Annalen, 119, 390-406.

Dulong, P. (1829). Recherches sur la chaleur spécifique des fluides élastiques. Annales, 41, 113-159.

Edlund, E. (1865). Quantitative Bestimmung der bei Volumveränderung der Metalle entstehenden Wärmephänomene und des mechanischen Wärme-Aequivalents, unabhangig von der inneren Arbeit des Metals. Annalen, 126, 539-572.

Eisenlohr, W. (1863). Lehrbuch der Physik (pp. 452-454). Stuttgart: Eigelhorn.

Elkana, Y. (1974). The discovery of the conservation of energy. London: Hutchinson Educational.

Estocquois, Th. (1858). Note sur l'équivalent mécanique de la chaleur. Comptes rendus, 46, 461-462.

Ewart, P. (1813). On the measure of moving force [read Nov 1808]. Memoirs of Manchester Philosophical Society, 2, 105-267.

Favre, (1858). Recherches sur l'équivalent mécanique de la chaleur. Comptes rendus, 46, 337-340.

Fick, A. (1866). Supplementband zu Müller-Pouillet's Lehrbuch der Physik für Mediciner. Medicinische Physik (2nd edition) (pp. 182-196). Braunschweig: Friedrich Vieweg.

Foucault, L. (1854). Feuilleton du Journal des Débats du Juin 8, 1854. Académie des sciences. Journal des Débats, June 8.

Ganot, A. (1856). Traité élémentaire de physique expérimentale et appliquée et de météorologie (6th edition) (pp. 310-311). Paris: The author.

Ganot, A. (1868). Traité élémentaire de physique expérimentale et appliquée et de météorologie (13th edition) (pp. 358-359). Paris: The author.

Garcia, R. (1987). Sociology of science and sociogenesis of knowledge. In B. Inhelder, et al. (Eds.), Piaget today (pp. 127-140). Hove, UK: Lawrence Erlbaum Associates.

Gréhant, N. (1869). Manuel de physique médicale (pp. 226-234). Paris: Germer Baillière.

Grove, W. (1850). The correlation of physical forces (2nd ed.). London: Samuel Highley.

Guedj, M. (2000). L' émergence du principe de conservation de l'énergie et la construction de la thermodynamique (Ph. D thesis). Université de Paris 7.

Haas, A. (1909). Die Entwicklungsgeschichte des Satzes von der Erhaltung der Kraft. Vienna: Alfred Hölder.

Halliday, D., \& Resnick, R. (1978). Physics (3rd ed.). New York: Wiley.

Hecht, E. (2007). Energy and change. The Physics Teacher, 45, 88-92.

Heimann, P. (1973). Conversion of forces and the conservation of energy. Centaurus, 66, 147-161.

Helm, G. (1887). Die Lehre von der Energie. Leipzig: Arthur Felix.

Helmholtz, H. (1845). Physiologische Wärmeerscheinungen. Fortschritte der Physik, 1, 346-355.

Helmholtz, H. (1847a). Über die Erhaltung der Kraft, eine physikalische Abhandlung. Berlin: G. Reiner.

Helmholtz, H. (1847b). Physiologische Wärmeerscheinungen. Fortschritte der Physik, 3, 232-245.

Helmholtz, H. (1848). Statik und Dynamik. Fortschtitte der Physik, 4, 66.

Helmholtz, H. (1849). Joule. Ueber das mechanische Aequivalent der Wärme, C.R. XXVIII, 132. Fortschritte der Physik, 241-242.

Helmholtz, H. (1853). On the conservation of force: A Physical Memoir (translated from the German). Scientific Memoirs, 6, 114-162.

Helmholtz, H. (1869/1847). Sur la conservation de la force (translated from German). Paris: Victor Masson.

Hicks, N. (1983). Energy is the capacity to do work-or is it? Physics Teacher, 21, 529-530.

Hiebert, E. (1959). Commentary on the papers of Thomas S. Kuhn and I. Bernard Cohen. In M. Clagett (Ed.), Critical problems in the history of science (pp. 391-400). Madison, WI: University of Wisconsin Press.

Hirn, G. A. (1854). Etudes sur les principaux phénomènes qui présent les frottements médiat. [Read on 28 June 1854]. Bulletin de la Société industrielle de Mulhouse, 26, 188-237.

Hirn, G. A. (1858). Recherches sur l'équivalent mécanique de la chaleur: présentées a la Société de physique de Berlin. Colmar: Bureau de la Revue d'Alsace.

Hirn, G. A. (1865). Théorie mécanique de la chaleur (2nd edition) (Vol. 1). Paris: Gauthier-Villars.

Holtzmann, C. (1846). On the heat and elasticity of gases and vapours (translated from a German pamphlet, Manheim, 1845). Scientific Memoirs, 4, 190-217.

Holtzmann, C. (1848). Ueber die Wärme und Elasticität der Gase und Dämphe. Annalen, 72, $183-191$.

Holtzmann, C. (1851). Ueber die bewegende Kraft der Wärme. Annalen, 82, 445-452. 
Hutchison, K. (1981). W. J. M. Rankine and the Rise of Thermodynamics. The British Journal for the History of Science, 14(1), 1-26.

Iona, M. (1973). Energy is the ability to do work. The Physics Teacher, 11, 259-260.

Jacobi, M. (1852). Mémoire sur la théorie des machines électromagnétiques [1850]. Annales, 34, 451-480. Jamin, J. (1859). Cours de physique de l'École Polytechnique, V.2 (pp. 432-440). Paris: Gauthier-Villars. Jamin, J. (1868). Cours de physique de l'École Polytechnique (2nd edition) (Vol. 2, pp. 430-467). Paris: Gauthier-Villars.

Joule, J. (1843). On the caloric effects of magneto-electricity, and on the mechanical value of heat [read on Aug. 21, 1843]. Philosophical Magazine, 23, 263-276; 347-355; 435-443.

Joule, J. (1845a). On the changes of temperature produced by the rarefaction and condensation of air. Philosophical Magazine, 26, 369-383.

Joule, J. (1845b). On the existence of an equivalent relation between heat and the ordinary forms of mechanical powers. Philosophical Magazine, 27, 205-207.

Joule, J. (1847a). On the mechanical equivalent of heat, as determined by the heat evolved by the friction of fluids. Philosophical Magazine, 31, 173-176.

Joule, J. (1847b). Expériences sur l'identité entre le calorique et la force mécanique. Comptes rendus, 25 , 309-311.

Joule, J. (1849). Sur l'équivalent mécanique du calorique. Comptes rendus, 28, 132-135.

Joule, J. (1850). On the mechanical equivalent of heat. Philosophical Transactions of the Royal Society of London [further Philosophical Transactions], 140, 61-82.

Joule, J. (1855). Note sur l'équivalent mécanique de la chaleur. Comptes rendus, 40, 310-312.

Joule, J. (1862). Note on the history of the dynamical theory of heat. Philosophical Magazine, 24, 121-123.

Joule, J. (1878). New determination of the mechanical equivalent of heat. Philosophical Transactions, 168, $365-385$.

Kemp, H. (1984). The concept of energy without heat or work. Physics Education, 19, 234-240.

Knoblauch, K. H. (1845). Wärmeentwicklung. Die Fortschritte der Physik, 317-46 (esp. 344-6).

Kuhn, Th. (1959). Energy conservation as an example of simultaneous discovery. In M. Clagett (Ed.), Critical problems in the history of science (pp. 321-356). Madison, WI: University of Wisconsin Press.

Kupffer, A. (1852). Bemerkungen über das mechanischen Aequivalent der Wärme [Dec 1851]. Bulletin de la Classe physico-mathématique de l'Académie Impériale des Sciences de St. Pétersbourg, 10(13), 193-197.

Laboulaye, Ch. (1847). Mécanique. Chaleur. Note. Dictionnaire des arts et manufactures, v. 2, col. 2524-2536 (esp. 2533-2534).

Laboulaye, Ch. (1858). Note sur des expériences à l'aide desquelles on détermine la valeur de l'équivalent mécanique de la chaleur. Comptes rendus, 46(773-75), 824-826.

Lancor, R. (2012). Using metaphor theory to examine conceptions of energy in biology, chemistry, and physics. Science \& Education. doi:10.1007/s11191-012-9535-8.

Laplace, P. (1822). Note sur la vitesse du son. Annales, 20, 266-268.

Laplace, P. (1846/1823). Traité de mécanique céleste. Book 12, ch. 3. Euvres de Laplace, v. 5. Paris: Imprimerie Royale.

Lehrman, R. (1973). Energy is not the ability to do work. Physics Teacher, 11, 15-18.

Lervig, P. (1972). On the structure of Carnot's theory of heat. Archive for the History of Exact Sciences, 9(3), 222-239.

Lippman, G. (1889). Cours de Thermodynamique. Paris: G. Carré, pp. 4-5, 51-64.

Mach, E. (1896). Die Principien der Wärmelehre historisch-kritisch entwickelt. Leipzig: J. A. Barth.

Mach, E. (1911/1872). History and root of the principle of the conservation of energy. Translation from the German. Chicago: The Open Court Publishing.

Masson, A. (1858). Sur la corrélation des propriétés physiques des corps. Annales, 53, 257-293.

Maxwell, J. C. (1871). Theory of heat (pp. 138-162). London: Longmans, Green \& Co.

Mayer, R. J. (1842). Bemerkungen über die Kräfte der unbelebten Natur. Annalen der Chemie und Pharmacie, 42, 233-240. Also in Mayer, J. R. (1893). Die Mechanik der Wärme (3rd edition). Stuttgart: J.G. Gotta, pp. 23-30.

Mayer, R. J. (1845/1867). Die organische Bewegung in ihrem Zusammenhange mit dem Stoffwechsel. Heilbronn: C. Drechsler. It was reprinted several times, for instance in Mayer, Die Mechanik der Wärme, Stuttgart, 1867, pp. 13-126 (esp. pp. 26-30).

Mayer, R. J. (1848). Sur la transformation de la force vive en chaleur, et réciproquement. Comptes rendus, 27, 385-387.

Mayer, R. J. (1849). Réclamation de priorité contre M. Joule, relativement à la loi de l'équivalence du calorique. Comptes rendus, 29, 534. 
Mayer, R. J. (1865/1842). Remarks on the forces of inorganic nature. In E. Youmans (Ed.), The Correlation and Conservation of Forces (pp. 251-258). New York: D. Appleton.

Mendoza, E. (1959). Contributions to the study of Sadi Carnot and his work. Archives Internationales d'Histoire des Sciences, 12(49), 377-396.

Müller, J. (1864). Lehrbuch der Physik und Meteorologie (6th edition), v. 2 (pp. 794-804). Braunschweig: F. Vieweg.

Müller, J. (1868). Lehrbuch der Physik und Meteorologie (7th edition), v. 2 (pp. 886-936). F. Vieweg: Braunschweig.

Papadouris, N. \& Constantinou, C. (2011). A philosophically informed teaching proposal on the topic of energy for students aged 11-14. Science \& Education, 20, 961-979.

Pambour, F. (1839a). Théorie de la machine a vapeur (pp. 68-113). Paris: Bachelier.

Pambour, F. (1839b). The theory of a steam engine (pp. 59-95). London: J. Weale.

Person, C. (1848). Relation entre le coefficient d'élasticité des métaux et leur chaleur latente de fusion. Chaleur latente du cadmium et de l'argent. Comptes rendus, 4, 258-261.

Person, C. (1854). Note sur l'équivalent mécanique de la chaleur. Comptes rendus, 39, 1131-1133.

Planck, M. (1887). Das Princip der Erhaltung der Energie. Leipzig: B. Teubner.

Poggendorff, J. C. (1848). Ueber der mechanischen Aequivalent der Wärme. Annalen, 73, 479-484.

Pouillet, C. (1856). Eléments de physique expérimentale et de météorologie (7th edition), v.1. Paris: L. Hachette.

Preston, Th. (1894). The theory of heat (pp. 604-622). London \& New York: Macmillan.

Privat-Deschanel, A. (1869). Traité élémentaire de physique (pp. 458-470). Paris: L. Hachette.

Quintus Icilius, G. (1855). Expérimental Physik (pp. 432-448). Hannover: Schmorl \& Seefeld.

Rankine, W. J. M. (1849). On an equation between the temperature and the maximum elasticity of steam and other vapours. The Edinburgh New Philosophical Journal, 47, 28-42.

Rankine, W. J. M. (1851a). On the mechanical theory of heat. Philosophical Magazine, 2(8), 61-65.

Rankine, W. J. M. (1851b). Abstract of a paper on the hypothesis of molecular vortices, and its application to the mechanical theory of heat. Proceedings of the Royal. Society of Edinburgh, 2(37), 275-288. read 4 Feb 1850.

Rankine, W. J. M. (1851b). On the centrifugal theory of elasticity, as applied to gases and vapours. Philosophical Magazine, 2(14, Dec, Suppl), 509-542.

Rankine, W. J. M. (1853a). On the mechanical action of heat, especially in gases and vapours [read Feb 4, 1850]. Transactions of the Royal Society of Edinburgh, [henceforth, Edinburgh Transactions]. 20, $147-190$.

Rankine, W. J. M. (1853b). On the general law of the transformation of energy. Proceedings of the Philosophical Society of Glasgow, 3(5), 276-280.

Reech, F. (1853). Théorie générale des effets dynamiques de la chaleur. Journal des mathématiques pures et appliquées, 18, 357-568.

Regnault, V. (1847). Relation des expériences entreprises par ordre de M. le Ministre des Travaux Publics...pour déterminer les principales lois et les données numériques qui entrent dans le calcul des machines a vapeur. Mémoires de l'Académie Royale de Sciences de l'Institut de France, 21, 3-767.

Regnault, V. (1853). Recherches sur la chaleur spécifique des fluides élastiques. Comptes rendus, 36, $676-687$.

Regnault, V. (1862/1853). Mémoire sur la chaleur spécifique des fluides élastiques. Mémoires de l'Académie Royale de Sciences de l'Institut de France, 26, 1-924.

Rizaki, A. \& Kokkotas, P. (2009). The Use of history and philosophy of science as a core for a socioconstructivist teaching approach of the concept of energy in primary education. Science \& Education. doi:10.1007/s11191-009-9213-7.

Schirra, N. (1991). Die Entwicklung des Energiebegriffs und seines Erhaltungkonzepts. Thun, Frankfurt am Main: H. Deutch.

Schröder van der Kolk, H. W. (1865). Ueber die Geschwindigkeit des Schalles. Annalen der Physik, 124, 453-470. An English translation: Schröder van der Kolk, H. W. (1865). On the velocity of sound. Philosophical Magazine, 30, 34-49, 391-392.

Schröder van der Kolk, H. W (1865). Studien über die Gase. Annalen der Physik, 126, 333-362. In English: Schröder van der Kolk, H. W. (1866). Studies on gases. Philosophical Magazine, 31, 124-137, $181-191$.

Secchi, R. (1869). L'unité des forces physiques. Paris: F. Savy.

Séguin, M. (1839). De l'influence des chemins de fer. Paris: Garilian-Goeury \& Dalmont.

Séguin, M. (1847). Note à l'appui de l'opinion émise par M. Joule, sur l'identité du mouvement et du calorique. Comptes rendus, 25, 420-422. 
Silliman, B. (1865). Principles of physics or natural philosophy (2 ${ }^{N D}$ edition) (pp. 498-501). Philadelphia: Th. Bliss.

Smith, C. (1976). William Thomson and the creation of thermodynamics: 1840-1855. Archive for the History of Exact Sciences, 16(3), 231-288.

Smith, C. (1998). The science of energy: A cultural history of energy physics in Victorian Britain. Chicago: University of Chicago Press.

Solomon, J. (1984). Alternative views of energy. Physics Education, 19, 56.

Steffens, H. (1979). James Prescott Joule and the concept of energy. New York: Science History Publications.

Tait, P. (1863). On the conservation of energy. Philosophical Magazine, 25, 429-431.

Tait, P. (1864). On the history of thermodynamics. Philosophical Magazine, 28, 288-292.

Tait, P. (1887). Conférences sur quelques-uns des progrès récents de la physique. Transl. from English. Paris: Gauthier-Villars.

Thomson, W. (1848). On an absolute thermometric scale founded on Carnot's theory of the motive power of heat. Philosophical Magazine, 33(222), 313-317.

Thomson, W. (1849). An account of Carnot's theory of the motive power of heat, etc. Edinburgh Transactions, 16, 113-155.

Thomson, W. (1850). On a remarkable property of steam connected with the theory of the steam-engine. Philosophical Magazine, 37, 386-389.

Thomson, W. (1852a). On the dynamical theory of heat, with numerical results deduced from Mr. Joule's equivalent of a thermal unit, and M. Regnault's observations on steam [read March 17, 1851]. Philosophical Magazine, 4, 8-21, 105-117, 168-176, 424-434.

Thomson, W. (1852b). Additional Note on the preceding Paper. Philosophical Transactions, 78-82.

Thomson, W. (1853). On the dynamical theory of heat, with numerical results deduced from Mr. Joule's equivalent of a thermal unit, and M. Regnault's observations on steam [read March 17, 1851]. Edinburgh Transactions, 20, 261-298.

Tresca \& Laboulaye, Ch. (1864). Recherches expérimentales sur la théorie de l'équivalent mécanique de la chaleur. Comptes rendus, 58, 358-360.

Trumper, R. (1990). Energy and a constructivist way of teaching. Physics Education, 25, 208-212.

Tyndall, J. (1862). Mayer, and the mechanical theory of heat. Philosophical Magazine, 24, 173-175.

Tyndall, J. (1863a). Heat considered as a mode of motion. New York: Appleton.

Tyndall, J. (1863b). Remarks on the dynamical theory of heat. Philosophical Magazine, 25, 368-387.

Tyndall, J. (1864). Notes on scientific history. Philosophical Magazine, 28, 25-51.

Verdet, É. (1852a). Fragment d'un mémoire de M. J-R. Mayer, de Heilbronn, ayant pour titre: Remarques sur les forces de la nature inanimée. Annales de Chimie et Physique, 34, 501-503.

Verdet, É. (1852b). Mémoire sur les effets calorifiques des courants magnéto-électriques, et sur l'équivalent mécanique de la chaleur; par M. Joule. Annales, 34, 504-508.

Verdet, É. (1852c). Mémoire sur les Changements de température produits par la Condensation et la Raréfaction de l'air; par M. Joule [papers of 1845 \& 1849]. Annales, 35, 118-125.

Verdet, É. (1852d). Mémoire sur la théorie dynamique de la chaleur; par W. Thomson. Annales de Chimie et Physique, 36, 118-124.

Verdet, É. (1863). Historic notice of the mechanical theory of heat. Philosophical Magazine, 25, 467-472.

Verdet, É. (1868/1862). Leçons sur la théorie mécanique de la chaleur professée en 1862 devant la Société Chimique de Paris. In Prudhon \& Violle (Eds.). Théorie mécanique de la chaleur, t. 1, in Euvres de l'É. Verdet, v. 7. Paris: Imprimerie Impériale, pp. I-CXLVIII.

Verdet, É. (1872). Théorie mécanique de la chaleur. In Prudhon \& Violle (Eds.). Théorie mécanique de la chaleur, t. 2, in Euvres de l'É. Verdet, v. 8 (pp. 1-265). Paris: Imprimerie Impériale.

Violle, J. (1872). Bibliographie de la théorie mécanique de la chaleur et de ses applications. In Prudhon \& Violle (Eds.). Théorie mécanique de la chaleur, t. 2, in Euvres de l'É. Verdet, v. 8. Paris: Imprimerie Impériale, pp. 267-338.

Walker, J. (2007). Physics (3rd ed.). Upper Saddle River, NJ: Pearson Prentice Hall.

Warren, J. (1982). The nature of energy. European Journal of Science Education, 4(3), 295-297.

Wartmann, E. (1848). Sur l'équivalent mécanique de la chaleur. Archives des sciences physiques, 8, 53.

Watts, M. (1983). Some alternative views of energy. Physics Education, 18, 213-217.

Wilhelmy, L. (1847). Wärmeentwickelung. Fortschritte der Physik, 3, 229-230.

Yagi, E. (1984). Clausius's mathematical method and the mechanical theory of heat. Historical Studies in the Physical Sciences, 15(1), 177-195.

Zeuner, G. (1869). Théorie mécanique de la chaleur (translated from German). Paris: Gauthier-Villars. 